\title{
Combined Spectroscopic Analysis of Beads from the Tombs of Kindoki, Lower Congo Province (Democratic Republic of the Congo)
}

(C) The Author(s) 2015

Reprints and permissions: sagepub.co.uk/journalsPermissions.nav DOI: 10.1 I77/00037028I56/6595 asp.sagepub.com

(SSAGE

\author{
Anastasia Rousaki', Alessia Coccato ${ }^{2}$, Charlotte Verhaeghe ${ }^{2}$, \\ Bernard-Olivier Clist ${ }^{3}$, Koen Bostoen ${ }^{3}$, Peter Vandenabeele ${ }^{2}$, \\ and Luc Moens'
}

\begin{abstract}
Raman spectroscopy and X-ray fluorescence (XRF) analysis are commonly applied to archaeological objects as a fast and nondestructive way to characterize the materials. Here, micro-Raman spectroscopy and chemometrics on handheld XRF results were used to completely characterize beads found during archaeological excavations in the Congo. Metallic objects, organogenic materials, and glass beads were studied. Special attention was paid to the glassy materials, as they seem to be of European production. The matrix family and crystalline phases assemblage, as well as the results from principal components analysis on the elemental data, were used to define groups of beads of similar composition, and therefore probably of similar origin. This research project establishes the feasibility of this approach to archaeological glasses, and can be used to confirm and support the bead typologies used by archaeologists.
\end{abstract}

\section{Keywords}

Micro-Raman spectroscopy, Handheld X-ray fluorescence, Chemometrics, Western Central-African beads, Colored glass, Archaeometry

Date received: 9 April 20I5; accepted: 14 September 2015

\section{Introduction}

Glass beads are commonly found in archaeological contexts from all over the world.' Special attention has been drawn to glass beads found in Africa in order to quantify, ${ }^{2}$ classify, ${ }^{3-9}$ provenance, ${ }^{10,11}$ and to evaluate the possibility of using them for dating purposes. ${ }^{2}$ Northern American glass beads traded by the Europeans have been chemically studied and identified as European productions on the basis of analytical results. ${ }^{13,14}$

The materials studied here come from a Western Central African context and are on archaeological grounds likely to be of European origin. Excavations have been carried out since 2012 in the Lower Congo Province of the Democratic Republic of the Congo as part of the KongoKing project hosted by Ghent University. ${ }^{15,16}$ The project is devoted to the study of the origins and early history of the Kongo kingdom through an interdisciplinary approach mainly involving archaeological and historical linguistics. The archaeological research has so far focused on two hilltops, Kindoki and Ngongo Mbata, associated with the historical capitals of two of the kingdom's provinces, i.e., Nsundi and Mbata.

This article provides an in-depth study of glass beads excavated on the site of Kindoki $\left(05^{\circ} 04^{\prime} 069 \mathrm{~S}\right.$; $\left.15^{\circ} 0 I^{\prime} 403 \mathrm{E}\right)$, situated some $10 \mathrm{~km}$ north-west from Kisantu, a small town on the National Road no. I between Kinshasa and Matadi and about $95 \mathrm{~km}$ as the crow flies south-west from Kinshasa. On this hilltop site, archaeological evidence has been uncovered for human settlement between the 14th and 19th centuries. Furthermore, a small

\footnotetext{
'Department of Analytical Chemistry, Ghent University, Ghent, Belgium ${ }^{2}$ Department of Archaeology, Ghent University, Ghent, Belgium

${ }^{3}$ Department of Languages and Cultures, KongoKing Research Group, Ghent University, Ghent, Belgium
}

Corresponding author:

Anastasia Rousaki, Department of Analytical Chemistry, Ghent University, Krijgslaan 28I, SI2, B-9000 Ghent, Belgium.

Email: raman@ugent.be 
cemetery of II tombs dated between the 18th and early 19th century has been fully excavated. In several tombs glass beads were found along with other material culture pointing to elite burials. ${ }^{17,18}$

In the cultural context of the Kongo kingdom, shell beads were used as personal adornment to symbolize fertility and femininity, as well as currency. Glass beads also had a strong link with magical rituals and with the display of social status. In more recent times, they were also used to symbolize femininity and as the main form of currency since 1858. ${ }^{12,13,18}$ The beads excavated in the Lower Congo, similarly to other archaeological findings in Africa and North America, seem to be of European manufacture (Venice, Amsterdam, Bohemia, France, and Bavaria). ${ }^{18}$

The aim of the study is to characterize each type of bead from a chemical point of view so that a better understanding of the materials can be achieved. This information can then be used for comparison among the beads of the present study, and for comparison with the productions of known workshops. We aim to obtain a deeper insight on glass-making technology (glass type, formers and stabilizers, colorants, opacifiers, etc.) and to support the archaeological interpretation of the excavated materials. Special focus is given to the glass beads, as they represent the vast majority of the studied samples and were often used in trading.

The beads recovered were nondestructively analyzed to provide chemical evidence in support of archaeological theories. Moreover, the chemical characterization of trade beads is strictly connected and complementary to typological studies on the same manufactures, ${ }^{9,17}$ which can dramatically improve our knowledge and understanding of large-scale processes, such as the production of glass beads in Europe, the introduction of these beads into African contexts, their circulation, and their use.

The proposed approach to the compositional question is nondestructive and multi-technique, as commonly chosen for the study of glassy materials. ${ }^{19-21}$ The combination of molecular techniques, such as Raman spectroscopy, with one or more other mainly elemental techniques ${ }^{22-24}$ is well-known for the study of glass archaeological artifacts, and is especially favored as it allows for the characterization of such materials in a nondestructive way. ${ }^{25}$ Moreover, in the last decade, Raman spectroscopy proved successful as an elemental probe for glasses: different glass types can be easily recognized based on their spectrum ${ }^{26-28}$ and valuable information on the network formers can be obtained via this vibrational spectroscopic technique. ${ }^{29,30}$ This chemical information should be easily implemented into the existing beads description systems. ${ }^{6-9,17,31,32}$ Moreover, the data extracted from handheld X-ray fluorescence ( $h X R F$ ) spectra were processed with such chemometric techniques as principal component analysis (PCA). As a next step, the outcome of this clustering processing has been combined with Raman spectroscopy results.

\section{Experimental}

\section{Samples}

Of the II excavated tombs in the Kindoki burial site (Congo), four contained beads. ${ }^{18}$ The majority of the excavated beads is made of glass. The colors observed in the set are white, blue, red, black, and transparent. Some metal objects and biogenic materials were also investigated. The sample names used for the discussion of the results correspond to published literature (Table I). Pictures of each type of bead (glass, biogenic materials, and metals) can be found as Supplementary Material for this paper (Table SI: a, b, c, d). All the measured samples came to our lab after being cleaned and consolidated.

\section{Instrumentation}

Micro-Raman Spectroscopy. Raman spectra were recorded with a Bruker Optics Senterra dispersive Raman spectrometer coupled with a microscope. Point measurements were performed using a red diode laser $(785 \mathrm{~nm})$ and a green $\mathrm{Nd}$ :YAG laser $(532 \mathrm{~nm})$. Spectra were obtained in the range of $60-2750 \mathrm{~cm}^{-1}$ and $80-2642 \mathrm{~cm}^{-1}$ for the $532 \mathrm{~nm}$ and the $785 \mathrm{~nm}$ laser, respectively, allowing the recording of both the Raman spectrum of glass and of the other mineral phases. The system uses a thermoelectrically cooled $\mathrm{CCD}$ detector, operating at $-65^{\circ} \mathrm{C}$. The power of each laser is software controlled. The laser power was maximum $29.7 \mathrm{~mW}$ and $13.5 \mathrm{~mW}$ for the $785 \mathrm{~nm}$ laser and the $532 \mathrm{~nm}$ laser, respectively. The measured spot size was generally $10 \mu \mathrm{m}$ for the glass characterization, and 4 to $2 \mu \mathrm{m}$ for the inclusions. The spectra were recorded without any cleaning or polishing of the surface, as this was not allowed by the archaeologists. In some cases, broken beads were available, and the spectra were recorded on the less altered internal surface. The instrument is controlled by Bruker OPUS software. The measuring time, laser power, and number of accumulations were set to obtain a good signalto-noise ratio. The collected Raman spectra were further processed in GRAMS (ThermoFisher Scientific). As regards the glass matrix characterization, a linear segment baseline was removed according to literature, ${ }^{23,29,30,33}$ and the glass massifs were subjected to curve fitting in the same software, in order to allow for reproducible results and for comparison with published data.

Handheld X-ray Fluorescence ( $h X R F$ ) Analyses. A commercial hXRF instrument (Olympus InnovX Delta) was used for elemental analysis of the beads. The measurements were conducted in air, inside a shielded chamber, and with the following conditions: tube voltage of $40 \mathrm{kV}$, tube current $79 \mu \mathrm{A}$, silicon-drift detector (SDD) and measuring time of $300 \mathrm{~s}$ (live time). The Rh-target based X-ray source produces a polychromatic $X$-ray beam of $5 \times 5 \mathrm{~mm}^{2}$. The instrument was connected to a portable computer, which 
Table I. Overview of the beads excavated at Mbanza Nsundi. For more information and the archaeological interpretation, see reference. ${ }^{18}$ The samples characteristics are provided (provenance, shape, dimensions, and color).

\begin{tabular}{|c|c|c|c|c|c|}
\hline & Amount & Type & Weight $(g)$ & $\begin{array}{l}\text { Measurements } \\
(\mathrm{mm})\end{array}$ & $\begin{array}{l}\text { Munsell color } \\
\text { chart }\end{array}$ \\
\hline \multicolumn{6}{|l|}{ Tomb 8} \\
\hline Wound, ridged tube, dark blue beads & 14 & Kindoki type I & $\begin{array}{l}10.16-15.9 \\
8\end{array}$ & $\begin{array}{l}\varnothing 16.5-18.4 \\
L 22.1-29.4\end{array}$ & $\begin{array}{l}\text { 7.5PB } 2 / 5 \\
\text { dark blue }\end{array}$ \\
\hline Wound, cylindrical, red-on-white beads & 1140 & Kindoki type 2 & $0.38-1.09$ & $\begin{array}{l}\varnothing 6.0-7.7 \\
L 7.5-11.3\end{array}$ & $\begin{array}{l}2.5 \mathrm{R} 3 / 10 \\
\text { ruby }\end{array}$ \\
\hline Wound, oblate, yellowish white bead & 1 & Kindoki type 3 & 1.25 & $\begin{array}{l}\varnothing 12.2 \\
L 7.5\end{array}$ & N9 white \\
\hline Wound, oblate, dark blue bead & 1 & Kindoki type 4 & 1.38 & $\begin{array}{l}\varnothing 1 \mathrm{I} .3 \\
\mathrm{~L} 8.2\end{array}$ & $\begin{array}{l}\text { 7.5PB } 2 / 5 \\
\text { dark blue }\end{array}$ \\
\hline Blown, round, silvered beads & 3 & Kindoki type 5 & 0.25 & $\begin{array}{l}\varnothing 10.5 \\
L \quad 12.5\end{array}$ & \\
\hline Copper bead & 1 & Kindoki type 6 & 0.44 & $\begin{array}{l}\varnothing 4.5 \\
L 4.9\end{array}$ & $\begin{array}{l}2.5 \mathrm{G} \\
6 / 4 \text { light almond } \\
\text { green }\end{array}$ \\
\hline Copper alloy hawk bells & 32 & Kindoki type 7 & I.7-I.22 & $\begin{array}{l}\varnothing 12.5-16.7 \\
L 7.8-9.9\end{array}$ & \\
\hline Pusula depauperata shell beads & 660 & & & $\begin{array}{c}\text { Small: L I0.7 } \\
\text { W } 9.1 \\
\text { H } 6.7 \\
\text { Big: L I } 5.2 \\
\text { W I } 2.9 \\
\text { H } 8.8\end{array}$ & \\
\hline $\begin{array}{l}\text { Timpanotonus fuscatus shell bead } \\
\text { Tomb II }\end{array}$ & $\mathrm{I}$ & & & & \\
\hline Wound, cylindrical, red-on-white beads & 268 & Kindoki type 2 & $0.38-1.09$ & $\begin{array}{l}\varnothing 6.0-7.7 \\
L 7.5-11.3\end{array}$ & $\begin{array}{l}2.5 \mathrm{R} 3 / 10 \\
\text { ruby }\end{array}$ \\
\hline $\begin{array}{l}\text { Pusula depauperata shell beads } \\
\text { Tomb } 9\end{array}$ & 272 & & & & \\
\hline $\begin{array}{l}\text { Wound, round, white with blue } \\
\text { floral inlay (blue decoration) }\end{array}$ & 3 & Kindoki types 8-9 & $0.56-0.74$ & $\begin{array}{l}\varnothing 6.8-7.1 \\
L 7.2\end{array}$ & $\begin{array}{l}5.0 Y 9 / 2 \\
\text { pearl }\end{array}$ \\
\hline $\begin{array}{l}\text { Wound, round, white with } \\
\text { blue floral inlay (incisions) }\end{array}$ & 1 & Kindoki types 8-9 & $0.57-0.69$ & $\begin{array}{l}\varnothing 5.7 \\
L 6.1\end{array}$ & $\begin{array}{l}\text { N9,5 bright } \\
\text { white }\end{array}$ \\
\hline Wound, round, blue with floral inlay & 2 & Kindoki type 10 & 0.49 & $\begin{array}{l}\varnothing 6.8-7.4 \\
L 6.4-6.8\end{array}$ & $\begin{array}{l}\text { 5.0PB } \\
3 / 4 \text { moonstone } \\
\text { blue }\end{array}$ \\
\hline $\begin{array}{l}\text { Wound, round, dark blue } \\
\text { with floral inlay }\end{array}$ & 1 & Kindoki type II & 0.46 & $\begin{array}{l}\varnothing 7.7 \\
L 8\end{array}$ & $\begin{array}{l}7.5 \mathrm{~B} 3 / 3 \text { dark } \\
\text { shadow blue }\end{array}$ \\
\hline Wound, round, dark blue beads & 2 & Kindoki type 12 & $0.75-0.83$ & $\begin{array}{l}\varnothing 8.3-9.6 \\
L 7.8-8.1\end{array}$ & N9 white \\
\hline $\begin{array}{l}\text { Wound, drop-shaped, white } \\
\text { with floral inlay }\end{array}$ & 5 & Kindoki type 13 & $0.58-0.78$ & $\begin{array}{l}\varnothing 6.6-7.0 \\
L 6.3-6.8\end{array}$ & $\begin{array}{l}\text { N9.5 bright } \\
\text { white }\end{array}$ \\
\hline Tomb 12 & & & & & \\
\hline $\begin{array}{l}\text { Wound, pentagonal-faceted, } \\
\text { black beads }\end{array}$ & 14 & Kindoki type I5 & $0.17-0.24$ & $\begin{array}{l}\varnothing 4.9-5.1 \\
L 5.9-6.1\end{array}$ & $\begin{array}{l}\text { I0.0YR } 4 / I \\
\text { lead gray }\end{array}$ \\
\hline Wound, oblate, black bead & 1 & Kindoki type 16 & 0.2 & $\begin{array}{l}\varnothing 5.9 \\
\text { L } 3.5\end{array}$ & $\begin{array}{l}\text { NI lamp } \\
\text { black }\end{array}$ \\
\hline
\end{tabular}


Table I. Continued.

\begin{tabular}{|c|c|c|c|c|c|}
\hline & Amount & Type & Weight (g) & $\begin{array}{l}\text { Measurements } \\
(\mathrm{mm})\end{array}$ & $\begin{array}{l}\text { Munsell color } \\
\text { chart }\end{array}$ \\
\hline $\begin{array}{l}\text { Drawn, round, navy blue, } \\
\text { white stripes }\end{array}$ & I & Kindoki type 17 & 0.26 & $\begin{array}{l}\varnothing 5.9 \\
L 5.1\end{array}$ & $\begin{array}{l}\text { I0.0B } 2 / 4 \\
\text { dark navy }\end{array}$ \\
\hline Beads of shell or coral & 2 & Kindoki type 18 & 0.01 & $\begin{array}{l}\varnothing 1.7 \\
L 2.2\end{array}$ & \\
\hline
\end{tabular}

allowed controlling and monitoring of the actual XRF measurements remotely. To take into account the effect of sample shape and dimensions, multiple spectra were recorded on each measured bead. The spectra were analyzed with the "Analysis of X-ray spectra by iterative least squares" (AXIL) and microxrf2 software tools. ${ }^{34,35}$ The contribution from the shielded chamber was measured, and it was concluded to be insignificant on the elemental analysis results. Only qualitative information can be obtained by these analyses, ${ }^{25,36}$ which can be of help in a first screening of the samples, to establish groups of similar glasses. ${ }^{36}$ The results of the spectra evaluation were collected in an Excel sheet, and then imported into IBM SPSS version 22.

Chemometrical Analysis on $h X R F$ Data. The results of the spectra evaluation as obtained by $\mathrm{AXIL}^{34}$ and microxrf2 ${ }^{35}$ programs were used for chemometrical calculations in SPSS Statistics 22 (IBM) software. ${ }^{37}$ The Kindoki types 6 and 7 beads, which are metallic, the organogenic beads (Pusula deupauperata and Timpanotonus fuscatus shells, as well as Kindoki type 18), and Kindoki type 5 beads, whose interior was coated with a silver-like layer, were excluded from chemometrical analysis and are treated as separate cases. The aim of the statistical analysis discussed in this paper is the clustering of glass beads on the basis of their hXRF spectrum and their correlation with the Raman grouping results on glass, in order to group the different origins of glass.

\section{Results and Discussion}

The samples originate from a funerary site in the Congo, which was in use during the 18th and 19th centuries. Of the I I excavated tombs, four contained beads. Of these tombs, two are attributed to women (nos. 8 and II) and two to men (nos. 9 and 12). The amount of beads in the female graves is much higher than in the male ones, and shells are only found there. ${ }^{18}$

Overall, three types of samples can be recognized: metallic objects, biogenic materials as shells and ivory, and, finally, glass beads. The selected analytical techniques are suitable for the characterization of these samples.

\section{Metals}

Raman spectroscopy is not applicable to metals ${ }^{38}$ while, on the other hand, it is a powerful tool for the characterization of corrosion products. ${ }^{39-41}$ To characterize the metals and alloys, XRF is easily applied. ${ }^{42}$ For the analyzed metallic objects, which show a strong corrosion, the information on the chemical composition is obtained from $h X R F$ analysis. The penetration of the X-rays depends on the matrix of the sample. This technique allows us to evaluate the overall composition of the studied artifact, core, and corrosion products at the same time. The qualitative information from the X-ray spectrum shows a different composition for the copper bead (Kindoki type 6) and the copper alloy hawk bells (Kindoki type 7). The Kindoki type 6 bead is composed of $\mathrm{Cu}$. Traces of other elements were also found in the corroded bead, such as $\mathrm{Zn}$ and Fe. The Kindoki type 7 bells consists of a $\mathrm{Cu}-\mathrm{Zn}$ alloy, with a minor Fe and $\mathrm{Ni}$ content (Figure I). Fe and $\mathrm{Zn}$ presence, is stronger for the copper alloy hawk bells than for the copper bead. The peaks of $\mathrm{S}$ and $\mathrm{Cl}$ are clearly visible, and are likely to be related with corrosion products formed on the surface of objects from burial environments (sulfates and chlorides, as well as phosphates and carbonates). It is important to keep in mind that the composition of an archaeological object is affected by burial. ${ }^{43}$ Metallic ions can be leached from the surface and substituted by different cations, and different salts can be deposited on the surface from water in the soil.

\section{Shells and Ivory}

With regard to the biogenic materials, two species of shellfish were identified (Pusula depauperata and Timpanotonus fuscatus), and ivory was suggested as the constituent of the two minuscule beads (Kindoki type 18). ${ }^{18}$ The cultural meaning of shell beads in daily life and in funerary rituals is described in another work. ${ }^{18}$ Micro-Raman analysis, in general, can differentiate between the two main polymorphs of $\mathrm{CaCO}_{3}$, i.e., aragonite and calcite. ${ }^{44,45}$

In neither of the shells was it possible to distinguish between calcite and aragonite ${ }^{46}$ (Figure 2). The carbonate structure in both cases was identified by the bands at approximately $1085,706,206$, and $152 \mathrm{~cm}^{-1} .47$ In a Pusula depauperata shell a band at $144 \mathrm{~cm}^{-1}$ is attributed to anatase. $^{48}$ In the Timpanotonus fuscatus shell two bands at 3075 and $3050 \mathrm{~cm}^{-1}$ were observed. These are likely to be $v(\mathrm{C}-\mathrm{H})$ vibrations from organic molecules. ${ }^{49}$ In fact, the application of different laser wavelengths and power together with weathering of the samples can shift the 


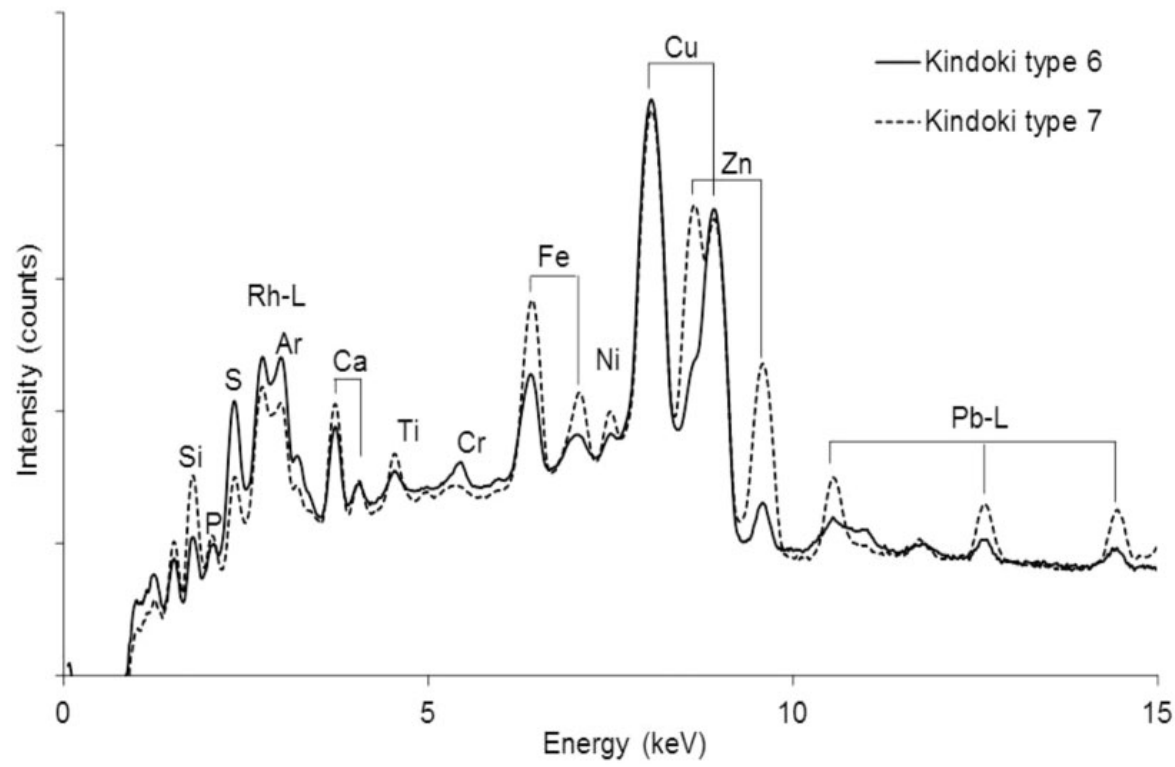

Figure I. Handheld XRF spectra from the metal objects, the Kindoki type 6 (copper bead) and Kindoki type 7 (copper alloy hawk bells).

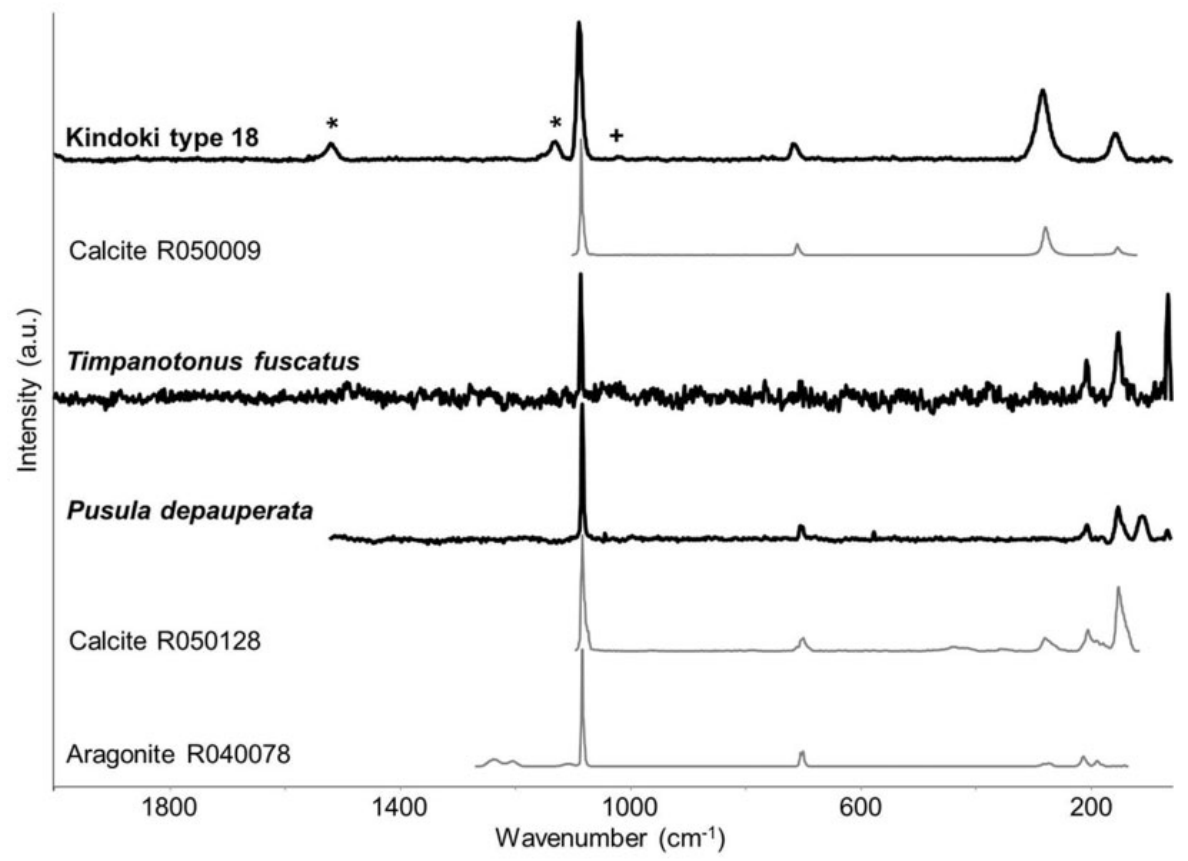

Figure 2. Raman spectra of the biogenic materials. Raman spectrum of the supposedly ivory beads (Kindoki type 18), which are actually shell or coral. The broad bands marked with * correspond to carotenoids and the band marked with + to anhydrite $\left(\mathrm{CaSO}_{4}\right)$. Reference spectra are from RRUFF database. ${ }^{46}$ Raman spectra of the shells Timpanotonus fuscatus and Pusula depauperata are also shown.

Raman bands, hampering the identification of the molecules. In both shells elemental analysis identified as major elements $\mathrm{Ca}$ along with minor ones, such as $\mathrm{Fe}$, $\mathrm{Mn}, \mathrm{Co}, \mathrm{Ni}$, and $\mathrm{Ti}$, probably attributed to the burial ground. In the Timpanotonus fuscatus shell $\mathrm{Sr}$ was also observed.

Moreover, the identification of ivory is feasible by Raman spectroscopy. ${ }^{50}$ The detection of $\mathrm{Ca}$ and $\mathrm{P}$ together in the 
hXRF spectrum of the beads of Kindoki type 18 are in agreement with the identification of the investigated material as ivory (hydroxyapatite $\mathrm{Ca}_{10}\left(\mathrm{PO}_{4}\right)_{6}(\mathrm{OH})_{2}$ ). Again, phosphate ions may come from the burial environment, and in this specific case, the extremely small size of the supposed ivory beads certainly influences the results of the hXRF analysis. ${ }^{36}$ Therefore, the results of Raman measurements have to be taken into account. The spectrum, collected on a fresh surface, does not correspond to that of ivory, ${ }^{50}$ while it shows the presence of calcite or aragonite $(1088,716$, 283 , and $\left.157 \mathrm{~cm}^{-1}\right)$, traces of anhydrite $\left(1019 \mathrm{~cm}^{-1}\right)$, and bands of organic molecules (Figure 2), which rejects the suggestion of ivory and puts forward the hypothesis of shell or coral as the used raw material for these tiny beads. The position of the $v_{1}$ and $v_{3}$ bands of carotenoids ( 1520 and $1130 \mathrm{~cm}^{-1}$ ) suggest the presence of $\beta$-carotene. ${ }^{45,51}$ The bands at $305 \mathrm{I}$ and 3075 might be overtones from a carotenoid structure, which is not optimally excited due to the fact that this specific shell was measured with the $785 \mathrm{~nm}$ laser. ${ }^{44,45}$ It is known that in general green lasers are the most preferable, due to resonance enhancement of the signal of carotenoids. ${ }^{44,45,51}$ The traces of anhydrite found on Kindoki type 18 may originate from contamination from the burial ground or as degradation product from weathering. Elemental analysis revealed the existence of other elements such as $\mathrm{Mg}, \mathrm{Sr}$, and $\mathrm{Zn}$, which may be associated with the high $\mathrm{Ca}$ content, and $\mathrm{Cr}$, $\mathrm{Fe}$, and Co, which may be contaminations from the burial environment.

\section{Glass}

To characterize the glass matrix, Raman spectra were collected mainly using the green laser. ${ }^{33} \mathrm{~A}$ typical Raman spectrum of glass shows two massifs corresponding to the silicate network vibrations, namely the bending vibration of the polymerized structure (centered at approximately $500 \mathrm{~cm}^{-1}$ ) and stretching of $\mathrm{Si}-\mathrm{O}$ bonds (centered at approximately $1000 \mathrm{~cm}^{-1}$ ). ${ }^{27,29,33}$ As the vibrational properties of chemical bonds are affected by their chemical environment, it has to be expected that the insertion of network modifiers, fluxing agents, and stabilizers will affect the spectral parameters of glassy materials. ${ }^{52,53}$ Actually, the replacement of $\mathrm{Si}^{4+}$ by other ions (alkali, alkali-earth, $\mathrm{Pb}$, etc.) creates non-bridging oxygens (NBO) in the $\mathrm{Si}-\mathrm{O}$ network. ${ }^{29}$ This depolymerization also affects glass stability. ${ }^{29}$ Moreover, silanol species are created on the surface of glass as result of cations leaching. The $\mathrm{Si}-\mathrm{OH}$ vibrations are centered around $980 \mathrm{~cm}^{-1} .54$ Table 2 summarizes the nomenclature of the silicate species according to the number of NBO. ${ }^{29,52,55,56}$ Table 3 reviews the correlations between Raman spectral parameters and glass properties. Some of the most interesting parameters from the compositional point of view are easily obtainable by the baseline corrected Raman spectrum, such as the $x v_{\max }^{22,28}$ and $x$
Table 2. $\mathrm{Q}^{\mathrm{n}}$ notation used to describe the glass network. ${ }^{29,52,55,56}$

\begin{tabular}{lll}
\hline Notation & Species & NBO \\
\hline $\mathrm{Q}^{4}$ & $\mathrm{SiO}_{2}$ & 0 \\
$\mathrm{Q}^{3}$ & $\mathrm{Si}_{2} \mathrm{O}_{5}$ & 1 \\
$\mathrm{Q}^{2}$ & $\mathrm{SiO}_{3}$ & 2 \\
$\mathrm{Q}^{1}$ & $\mathrm{Si}_{2} \mathrm{O}_{7}$ & 3 \\
$\mathrm{Q}^{0}$ & $\mathrm{SiO}_{4}$ & 4 \\
\hline
\end{tabular}

$\delta_{\max }^{22,28,57}$ positions. These maxima are useful for a first discrimination among glass types. ${ }^{28}$

Figure 3 shows the raw (top) and the baseline corrected Raman spectrum one (bottom): a segment baseline was subtracted, with fixed points at approximately 150, 700, 830 , and $1200 \mathrm{~cm}^{-1} \cdot 23,28$ The baseline corrected spectrum is then deconvoluted by using Gaussian curves (Figure 3): during this step, it is possible to identify the relative contribution of the different silicatic species $\mathrm{Q}^{\mathrm{n}}$ to the glassy network. Moreover, it is possible to quantify the ratio between polymerized species, mainly contributing to the bending massif, with respect to the non-polimerized units, which can be related with the stretching massif. This ratio is well known as the polymerization index $I_{P}$ and is calculated as the area ratio $A_{500} / A_{1000}{ }^{23,27-29}$ It has been demonstrated to be in relation with the firing temperature of the glass itself, ${ }^{23}$ and it can be combined with the stretching and bending positions in order to have an idea on the glass chemistry. ${ }^{22,28}$

Moreover, it is known that the insertion of other cations than $\mathrm{Si}$ modifies the linking of the tetrahedral units, and that some cationic species are preferably found in relation with specific silicatic species, as for example divalent stabilizers which favor the formation of $\mathrm{Q}^{2}$ species, thus enhancing the contribution of the $\mathrm{vQ}^{2}$ band at approximately $950 \mathrm{~cm}^{-1}$ to the stretching region.

Many studies of glass materials which combined Raman spectroscopy with elemental techniques succeeded in establishing compositional correlations. ${ }^{22,23,28-30}$ Such a combination seems of primary importance, as some elements such as $\mathrm{Ca}$ and $\mathrm{Pb}$ are present both in the glass matrix and as colorants/opacifiers. Micro-Raman spectroscopy can easily distinguish between the two possibilities. However, quantitative elemental techniques are commonly applied such as X-ray based techniques, ${ }^{58}$ instrumental neutron activation analysis (INAA), ${ }^{13}$ and laserablation inductively coupled plasma mass spectroscopy (LA-ICP-MS). ${ }^{11,43}$

Correlations between the glass chemistry and the Raman parameters have been established for the amount of $\mathrm{Si}$, of stabilizers and flux (alkali and earth alkali ions), and of lead, which may act either as a network modifier or as a former. ${ }^{30}$ An overview of the chemical characterization of 
the glass based on the Raman spectra through the above mentioned observations is summarized in Table 3.

Concerning the identification of the coloring agents, it has to be kept in mind that transition metal ions dispersed in a glassy matrix cannot be detected by means of Raman spectroscopy. ${ }^{33}$ On the other hand, the optical properties of glass are related to the presence of crystals formed during the cooling process or to the dispersion of pigment granules. ${ }^{33}$ Metal nanoparticles are also reported to be used as colorants for glass. ${ }^{33}$

Black Glass: Kindoki Types 15 and 16. The black glass shows in both cases a purplish hue under the microscope light. This can be correlated to the presence of $\mathrm{Mn}^{20}$ The baseline corrected spectra, the band positions obtained after deconvolution, and the estimation of lead and stabilizers from the spectral parameters (see Table 3) all agree towards a mixed alkali composition for the glass, and a firing temperature slightly lower than $1000^{\circ} \mathrm{C}$. Such a glass is expected to be stable ${ }^{29}$ (see Figure 4, spectra a and b).

Blue Glass: Kindoki Types I, 4, II, and I7; Blue Decoration on Kindoki Type 8. Among the blue glasses, different Raman signatures can be observed. The blue bead Kindoki type II (with incisions; Figure 4, spectrum c) has a signature which is similar to that of the blue glass of the striped bead Kindoki type 17 (Figure 4, spectrum d). The band positions are compatible with a mixed alkali glass composition. The value of $I_{B}$ combined with the maximum of the bending massif, suggests the use of $\mathrm{Ca}$ and $\mathrm{K}$ as fluxing and stabilizers in the glass. ${ }^{22}$

Another type of Raman spectrum is observed for the blue beads of Kindoki types I and 4 (Figure 4, spectrum $\mathrm{f}$ ). In addition to the stretching and bending massifs ( $1100 \mathrm{~cm}^{-1}$ and the $535 \mathrm{~cm}^{-1}$, respectively), which suggest a mixed alkali composition, $\mathrm{Ca}_{3}\left(\mathrm{PO}_{4}\right)_{2}$ is identified on the basis of its main vibration at $960 \mathrm{~cm}^{-1} .{ }^{19}$ It is likely that most of the calcium detected by hXRF is related to this compound, more than to its presence as a stabilizer inside the glass network.

These blue beads seem to have been produced in Germany (Fichtelgebirge, Bavaria; 18th-19th centuries), and were typically traded via Amsterdam and other ports to Africa. ${ }^{5,18}$ Finally, the blue decoration present on some of the beads of Kindoki types 8 and 9 was analyzed. It showed a Raman spectrum whose maxima are 1097 and $56 \mathrm{~cm}^{-1}$, respectively, for the stretching and bending vibrations. No lead is expected in this type of glass. ${ }^{22,30}$ Various independent parameters agree on a mixed alkali composition for this glass (see Table 3).

Corroded Blue Glass: Kindoki Types 10 and 12. These beads are strongly corroded. They both show a blue color under direct illumination. Kindoki type 10 bead presents incisions 


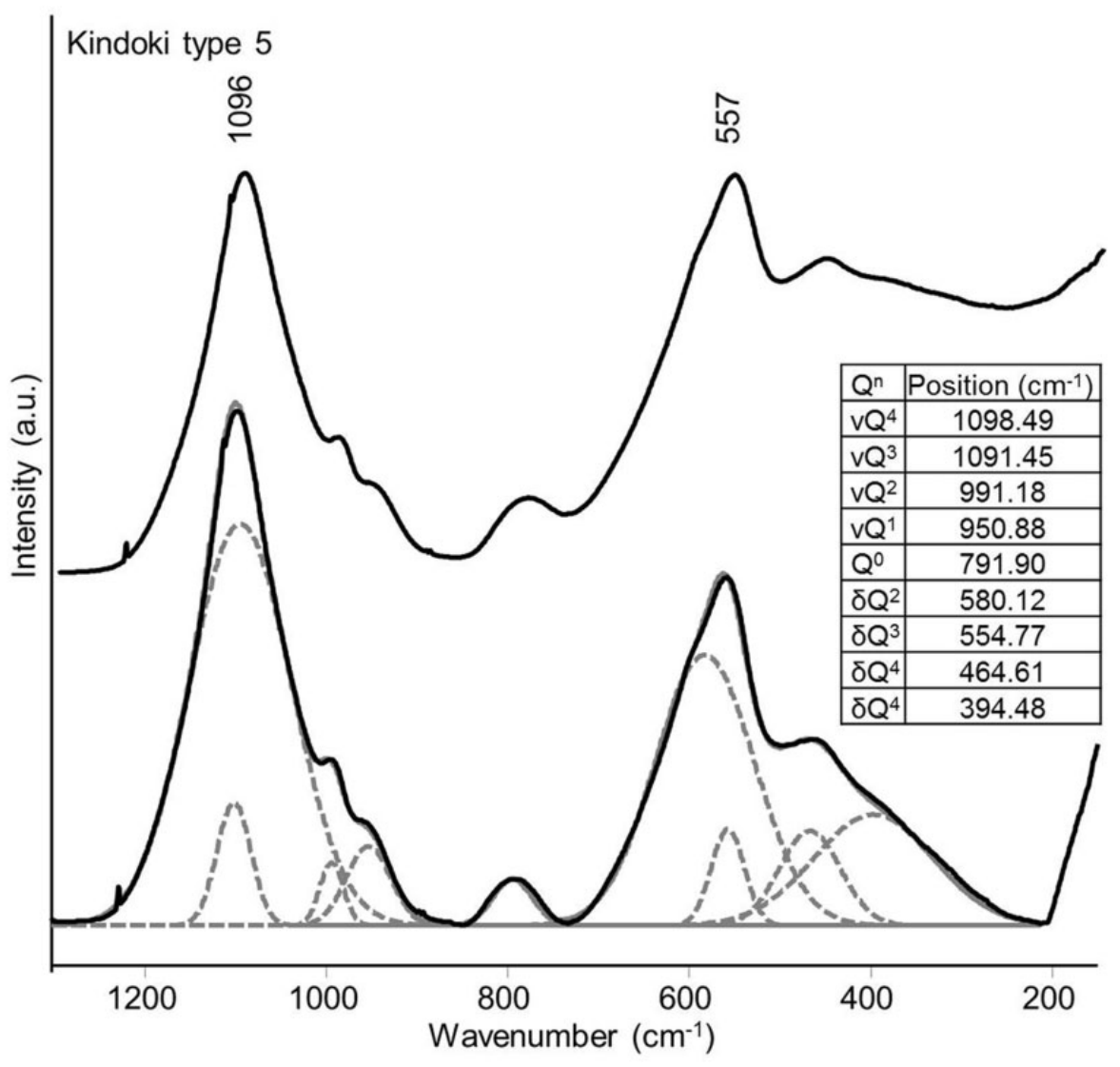

Figure 3. Example of the spectral processing of Raman spectra of glass. First, the raw spectrum (top) is baseline corrected. The resulting spectrum is band deconvoluted using Gaussian curves. The band positions and assignments are given in the inset.

on its surface, where a decoration (now lost) was applied. Due to the thick corrosion crust, Raman spectroscopy was not able to identify the glassy structure.

One Raman spectrum was collected on the broken surface (less altered) of Kindoki type 12 bead. The stretching and bending maxima are at 1085 and $590 \mathrm{~cm}^{-1}$. Again, a mixed alkali composition is established based on different observations, such as $v^{2}$ contribution and band positions.

White Glass: Kindoki Types, 2, 3, 8, 9, 13, and 17. As already observed, different types of glass can be identified in the same color group. This applies to the blue beads (previously described) and to the white ones. The white core of the red-on-white beads (Kindoki type 2; Figure 4, spectrum h) shows the lowest observed value among the studied beads, for the stretching maximum position. It is known that lead affects the $v \mathrm{Q}^{3}$ position and the $\mathrm{vQ}^{2}$ relative area, and therefore in this case some lead has to be expected as a network modifier. ${ }^{30}$ Moreover, the calculated $I_{P}$ value is the lowest recorded among the samples, and it can confirm the presence of lead, as it was added in order to lower the firing temperature of the glass. ${ }^{28}$ The bending maximum $\left(452 \mathrm{~cm}^{-1}\right)$, again, supports a mixed $\mathrm{Na}-\mathrm{Pb}$ composition. ${ }^{22}$
Moreover, the band of a lead-based opacifier is clearly visible (see next sections).

A different type of glass is found for the white glass bead Kindoki type 3 (Figure 4, spectrum g). The main band of $\mathrm{Ca}_{3}\left(\mathrm{PO}_{4}\right)_{2}$ is visible at $960 \mathrm{~cm}^{-1}$, $^{19}$ in addition to the glass features. This bead type corresponds to other findings in the Congo and to beads in museums. ${ }^{5,18}$ It was believed to be a product of Holland, but again it matches the Bavarian productions of Fichtelgebirge. ${ }^{18}$ Moreover, additional bands overlapping with the bending massif are detected. The broad bands at 606 and $446 \mathrm{~cm}^{-1}$ can be assigned to rutile. ${ }^{59}$ The $I_{P}$ value and $Q^{3}$ band position indicate that the amount of $\mathrm{Si}$ in this bead is high (approximately 80\%), and that the structure is well polymerized.

The opaque white glass (Kindoki types 8, 9, and 13) was tested with both the red and the green lasers of the instrument. All the Raman spectra showed the band of lead arsenate $\left(\mathrm{AsO}_{4}\right)_{2} \mathrm{~Pb}_{3}$ at approx. $824 \mathrm{~cm}^{-1}$. 60,61 However, the spectra collected with the green laser are difficult to relate to a glassy material, as the baseline correction with segments, as described in the literature, is not straightforwardly applicable. ${ }^{23,28-30}$ All the spectra of opaque white glass beads were acquired with the $785 \mathrm{~nm}$ laser. The spectra are dominated by an intense luminescence 


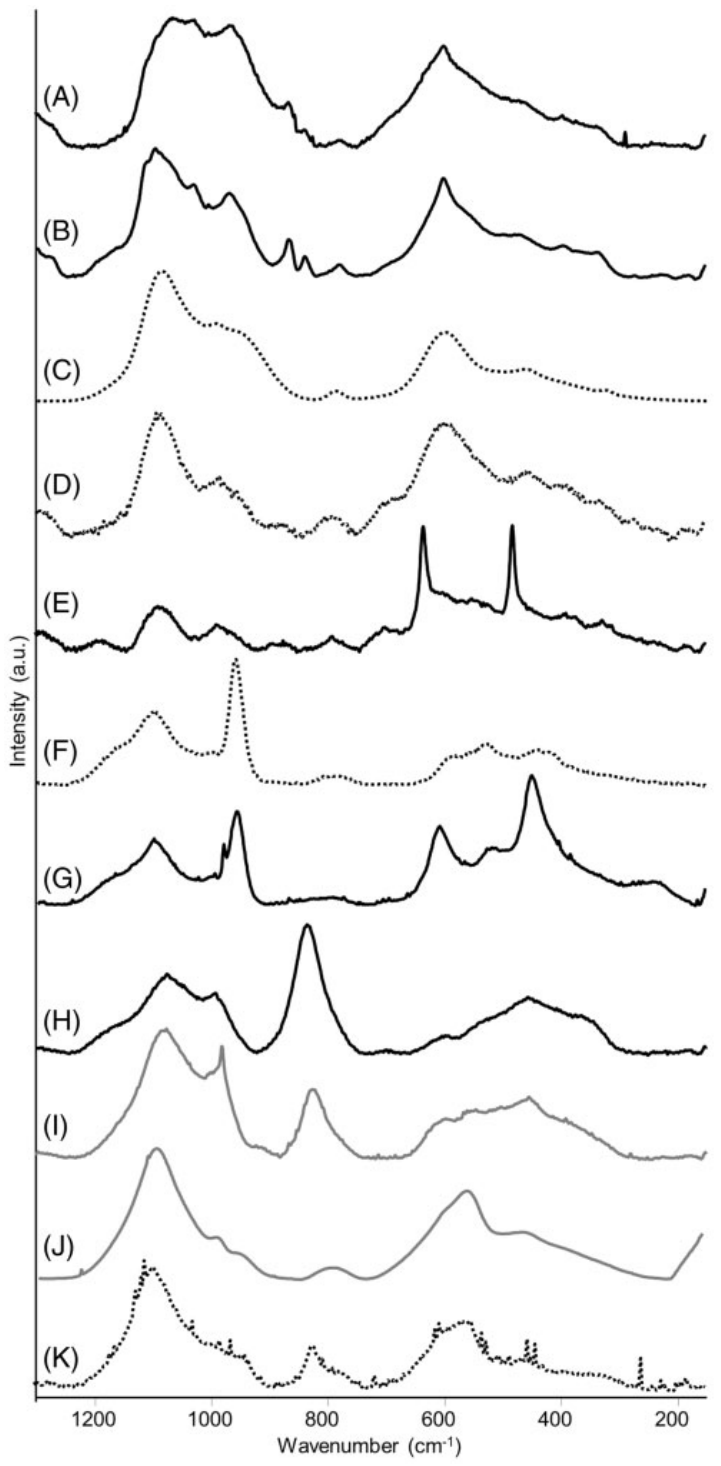

Figure 4. Stack plot of representative Raman spectra of the distinguishable types of studied glass beads. Full lines indicates either black or white color of the glass, dashed lines are for the blue glass, full gray lines are used for the red and transparent glasses. (a) Kindoki type 15, black; (b) Kindoki type 16, black; (c) Kindoki type II, blue; (d) Kindoki type I7, blue; (e) Kindoki type 17, white; (f) Kindoki type I, blue; (g) Kindoki type 3, white; (h) Kindoki type 2, white; (i) Kindoki type 2, red; (j) Kindoki type 5, transparent; (k) Kindoki type 8-9, blue decoration.

feature centered at approximately $1350 \mathrm{~cm}^{-1}$. 62 The main Raman band of lead arsenate $\left(\left(\mathrm{AsO}_{4}\right)_{2} \mathrm{~Pb}_{3}, 823 \mathrm{~cm}^{-1}\right)^{60,61}$ is also clearly visible, and characterizes all the spectra from this grouping. Also, a weak band at ca. $767 \mathrm{~cm}^{-1}$ is attributable to borosilicatic features in the glass. ${ }^{63} \mathrm{~A}$ downshift in the expected center of the bending envelope is observed. The stretching massif is composed of two bands at approximately 1040 and $980 \mathrm{~cm}^{-1}$. Such band positions do not correspond to published values, probably because the preferred wavelength for glass analysis is green or blue. ${ }^{27}$ The interpretation of these spectra is therefore limited.

The white stripes on the Kindoki type 17 bead gave a Raman spectrum very similar to that from the blue glass of the same bead (Figure 4, spectra $d$ and e), with superimposed the features of calcium antimonate $\left(\mathrm{Ca}_{2} \mathrm{Sb}_{2} \mathrm{O}_{7}\right)^{20,22,24}$ These, at 630 and $480 \mathrm{~cm}^{-1}$, make the interpretation of the Raman spectrum of glass not straightforward. However, the presence of lead can be excluded on the basis of the $\mathrm{vQ}^{3}$ band position. ${ }^{30}$

Red Glass: Kindoki Type 2. As already observed for the white glass of this same bead, a certain amount of lead can be present in the glassy network, as suggested by the slightly downshifted $v Q^{3}$ band position $\left(1086 \mathrm{~cm}^{-1}\right)$. The lead presence has an influence on the firing temperature of the glass, and therefore on the calculated $I_{P}$ value, which is lower than for the other beads of mixed alkali composition. However, when comparing the value of the maximum of the bending massif with literature, the suggestion is made that the glass is based on sodium and lead. ${ }^{22}$ The red and white glass from this typology are very similar, suggesting that the same glass was used to produce them, with different additives for obtaining the white and red colors (Figure 4, spectra $h$ and i).

Transparent Glass: Kindoki Type 5. The blown beads of Kindoki type 5 show the signature of mixed alkali silicate glass (Figure 3 and Figure 4, spectrum j), with no lead in the silicatic network. The absence of lead explains the relatively high firing temperature value as obtained by the $I_{P}$ value. ${ }^{23}$

The spectrum of this transparent glass can be anyway related to the blue decorations on Kindoki types 8 and 9 beads, which shows the band of lead arsenate ${ }^{64}$ in addition to the glass related massifs (Figure 4, spectrum k).

Notwithstanding the chemical homogeneity of the glass, different groupings can be highlighted:

I. Black beads (Kindoki types 15 and 16) and blue bead Kindoki type II

2. Kindoki type 17: the white and blue glasses share the same matrix, and colorants/opacifiers were likely added to the same glass recipe

3. Blue glass of decoration of Kindoki type 8-9 and transparent glass of Kindoki type 5

4. Kindoki types I, 3, and 4 due to the presence of calcium phosphate. The two blue beads are similar to each other

5. The red and white glasses of Kindoki type 2 beads are similar, and might contain some $\mathrm{Pb}$ in the matrix as from the Raman spectral parameters

Representative spectra from each bead type are collected in Figure 4. All the studied samples belong to a mixed alkali glass family, with the exception of type 2, which probably contains some lead as well (on the basis of spectral parameters, see Table 3). 


\section{Crystalline Phases of Glass, Opacifiers, and Coloring Agents}

Black Beads. The main characteristics of these beads (Kindoki types 15 and 16) are the different phases of manganese oxides found with micro-Raman spectroscopy and Fe and $\mathrm{Mn}$ found from elemental analysis. The approximate $\mathrm{Fe} / \mathrm{Mn}$ counts ratio in the two black glasses is 0.6 and 2.1 , respectively. Specifically, for Kindoki type 15, bands at 657 and $630,650,636,630 \mathrm{~cm}^{-1}$ correspond to $\alpha-\mathrm{Mn}_{2} \mathrm{O}_{3}$, $\alpha-\mathrm{MnO}_{3}$ or $\beta-\mathrm{MnO}_{2}$ or $\mathrm{Mn}_{3} \mathrm{O}_{4}, \gamma-\mathrm{Mn}_{2} \mathrm{O}_{3}$, respectively. ${ }^{65}$ The bands at 648,643 , and $594 \mathrm{~cm}^{-1}$ can be assigned to MnO. ${ }^{65}$ Specifically, the band at $643 \mathrm{~cm}^{-1}$ could be also attributed to spinel $\mathrm{Fe}_{3} \mathrm{O}_{4}{ }^{60}$ with actually a more dominant theory based on the color of the bead. The bands at 545 and $420 \mathrm{~cm}^{-1}$ can be assigned to $\mathrm{MnO}^{65}$ or magnetite 66,67 for the first one and magnetite for the second. A band at $432 \mathrm{~cm}^{-1}$ is attributed to $\mathrm{v}_{2} \mathrm{PO}_{4}{ }^{3-}$ vibration mode. ${ }^{68}$ The presence of $\mathrm{Mn}$ is also responsible for the purplish hue of the glass. " For Kindoki type 16, bands at 1732 and $1453 \mathrm{~cm}^{-1}$ may imply the presence of a Ca-oxalate (Weddellite, $\mathrm{Ca}\left(\mathrm{C}_{2} \mathrm{O}_{4}\right) \cdot 2 \mathrm{H}_{2} \mathrm{O}$ ). This compound is likely to be a degradation product. ${ }^{69} \mathrm{~A}$ band at $599 \mathrm{~cm}^{-1}$ is corresponding to $\mathrm{MnO}^{65}$ and one at $141 \mathrm{~cm}^{-1}$ to anatase. ${ }^{48}$ Two bands at 865 and $836 \mathrm{~cm}^{-1}$ are considered to be vibrations from silicates, namely olivine $(\mathrm{Mg}, \mathrm{Fe})_{2} \mathrm{SiO}_{4}{ }^{70}$ Elemental analysis revealed common elements for the two beads such as $\mathrm{Ca}, \mathrm{Ti}, \mathrm{Mn}, \mathrm{Fe}$, and $\mathrm{Ni}$. Minor elements inside the Kindoki type I 5 mixture could be considered Co, $\mathrm{Cu}$, and $\mathrm{Cr}$, with $\mathrm{Co}, \mathrm{Sr}, \mathrm{Pb}$, and $\mathrm{Zn}$ for Kindoki type $\mathrm{I} 6$.

Blue Beads. Four types of beads are included in the group of blue beads, having shades from dark blue to navy blue (Kindoki types I, 4, II, and 17). The major characteristic of the blue beads is the presence of different phases of manganese oxides, identified by micro-Raman spectroscopy, which, together with Co, identified with $\mathrm{hXRF}$, form the color of the artifacts. Specifically, on Kindoki type I, bands at 545, 540, $537 \mathrm{~cm}^{-1}$ are attributed to $\mathrm{MnO}$ and a band at $526 \mathrm{~cm}^{-1}$ corresponds to $\beta-\mathrm{MnO}_{2}{ }^{65}$ Moreover an intense peak at $960 \mathrm{~cm}^{-1}\left(v_{\mathrm{I}} \mathrm{PO}_{4} \text { vibration mode }\right)^{33,68}$ in combination with the amount of $\mathrm{Ca}$ found from the elemental analysis imply the existence of calcium phosphate $\left(\beta-\mathrm{Ca}_{3}\left(\mathrm{PO}_{4}\right)_{2}\right.$, as opacifier. Bands at 150 and $140 \mathrm{~cm}^{-1}$ correspond to feldspars (Ca-bearing plagioclase) ${ }^{66}$ and anatase ${ }^{48}$, respectively. On Kindoki type 4 , due to high luminescence, no managanese oxides were identified and it was only possible to retrieve one single band at $960 \mathrm{~cm}^{-1}\left(v_{1} \mathrm{PO}_{4}\right.$ vibration mode) probably indicating the presence of calcium phosphate $\left(\beta-\mathrm{Ca}_{3}\left(\mathrm{PO}_{4}\right) \cdot{ }^{33,68}\right.$ From the elemental analysis on Kindoki type I and type 4, considerable amounts of $\mathrm{Ca}, \mathrm{P}, \mathrm{Fe}, \mathrm{Mn}, \mathrm{Co}$, and $\mathrm{Ni}$ were found. Also, $\mathrm{As}$ and $\mathrm{Bi}$ were identified in the mixtures. The coloring agent for the dark blue color was probably Co along with $\mathrm{Mn}$. The differences on minor elements for both beads are $\mathrm{Pb}$ and $\mathrm{Rb}$ for Kindoki type $\mathrm{I}$ and $\mathrm{Cr}$ and $\mathrm{Pb}$ for Kindoki type 4. On Kindoki type II, micro-Raman spectroscopy revealed a band at $544 \mathrm{~cm}^{-1}$ attributed to $\mathrm{MnO}^{65}$ or magnetite $\left(\mathrm{Fe}_{3} \mathrm{O}_{4}\right){ }^{66}$ On Kindoki type 17, a band around $960 \mathrm{~cm}^{-1}$ is attributed to $v_{1} \mathrm{PO}_{4}$ vibration mode, probably again forms calcium phosphate $\left(\beta-\mathrm{Ca}_{3}\left(\mathrm{PO}_{4}\right)_{2}{ }^{33,68}\right.$ Moreover, from the white stripes on the blue bead, calcium antimonate $\left(\mathrm{Ca}_{2} \mathrm{Sb}_{2} \mathrm{O}_{7}\right)$ was identified as opacifier by the bands at 842,634 , and $480 \mathrm{~cm}^{-1} \cdot{ }^{20-22}$ The orthorhombic phase of calcium antimonate is identified here according to spectra of synthethic products. ${ }^{20}$ From the blue area, a band at $631 \mathrm{~cm}^{-1}$ may be indicative of the presence of a phase of manganese oxide $\left(\alpha-\mathrm{Mn}_{2} \mathrm{O}_{3}\right.$ or $\beta-\mathrm{MnO}_{2}$ or $\left.\gamma-\mathrm{Mn}_{2} \mathrm{O}_{3}\right){ }^{65}$ Anatase was also identified inside the mixture by the band at $144 \mathrm{~cm}^{-1}$. A band at $890 \mathrm{~cm}^{-1}$ is related to the symmetric stretching of tetrahedral silicate groups with one $\left(\mathrm{Si}_{2} \mathrm{O}_{5}\right)$, two $\left(\mathrm{SiO}_{3}\right)$, three $\left(\mathrm{Si}_{2} \mathrm{O}_{7}\right)$, and four $\left(\mathrm{SiO}_{4}\right)$ non-bridged oxygens ${ }^{52,55,56}$ (see also Table 2). For Kindoki types $\mathrm{II}$ and 17 , the major components in the mixtures are again $\mathrm{Ca}, \mathrm{Fe}, \mathrm{Co}, \mathrm{Mn}$, and $\mathrm{Ni}$. On Kindoki type II, the intensity of $\mathrm{Mn}$ is less than that of Fe, something that is reversed for Kindoki type 17. Other elements identified in the two beads are $\mathrm{Ti}, \mathrm{Cu}, \mathrm{As}, \mathrm{Sr}, \mathrm{Pb}$, and $\mathrm{Bi}$ for Kindoki type II and $\mathrm{Cu}, \mathrm{As}$, Sr, and Sb for Kindoki type 17. Lastly, $\mathrm{Co}$ and $\mathrm{Ni}$ are much more correlating than the other elements on the blue beads. There is some published literature ${ }^{|3,21,31,43,7|-74}$ (Table 4) indicating correlations between $\mathrm{Co}$ and other elements found in the mixture,

Table 4. Correlations of elements with Co and indications of the possible origin of the source mineral.

\begin{tabular}{|c|c|c|}
\hline Correlations of Co with: & $\begin{array}{l}\text { Co mineral } \\
\text { provenance }\end{array}$ & Reference \\
\hline As & Germany & 13 \\
\hline $\mathrm{Cu}-\mathrm{Ni}-\mathrm{Sn}$ & - & 21 \\
\hline $\mathrm{Ni}, \mathrm{As}$ & $\begin{array}{l}\text { Germany } \\
\quad \text { (Schneeberg) }\end{array}$ & 31,71 \\
\hline $\mathrm{Mg}, \mathrm{Fe}, \mathrm{Ni}, \mathrm{Cu}, \mathrm{Zn}, \mathrm{Pb}, \mathrm{Sn}, \mathrm{Sb}$ & - & 43 \\
\hline $\mathrm{Fe}, \mathrm{Cu}, \mathrm{Pb}, \mathrm{Sn}, \mathrm{Zn}$ & Levantine & 71 \\
\hline As, Bi (Fe, Ni, Cu) & $\begin{array}{l}\text { Germany } \\
\text { (Erzgebirge) }\end{array}$ & 72 \\
\hline $\mathrm{Fe}$ & - & 72 \\
\hline $\mathrm{Ni}-\mathrm{Mo}-\mathrm{Fe}$ & $\begin{array}{l}\text { Germany } \\
\text { (Erzgebirge) }\end{array}$ & 73 \\
\hline $\mathrm{As}-\mathrm{Ni}-\mathrm{Bi}-\mathrm{Mo}-\mathrm{U}-\mathrm{Fe}$ & $\begin{array}{l}\text { Germany } \\
\quad \text { (Schneeberg) }\end{array}$ & 73 \\
\hline $\mathrm{Zn}-\mathrm{Pb}-\mathrm{In}-\mathrm{Fe}$ & $\begin{array}{l}\text { Germany } \\
\text { (Freiberg) }\end{array}$ & 73 \\
\hline $\mathrm{Sb} ; \mathrm{Cu} ; \mathrm{Mn} ; \mathrm{Zn}-\mathrm{Ni}-\mathrm{Fe}-\mathrm{Cr}-\mathrm{As}$ & $\begin{array}{l}\text { Unknown } \\
\text { (Near East?) }\end{array}$ & 73 \\
\hline $\mathrm{Mn}, \mathrm{Ni}, \mathrm{Zn}$ & Africa (Egypt) & 74 \\
\hline
\end{tabular}


but no general conclusions can be made for the group of blue beads described in this paper.

Corroded Blue Beads. Kindoki types 10 and 12 beads belong initially to the blue beads group. Macroscopically they appear severely corroded so they are treated separately from the other blue beads. Different phases of manganese oxides were identified in the mixture of Kindoki type 10. Bands at 635,592 , and $529 \mathrm{~cm}^{-1}$ are attributed to $\gamma-\mathrm{Mn}_{2} \mathrm{O}_{3}$ or $\beta-\mathrm{MnO}_{2}, \mathrm{MnO}$, and $\beta-\mathrm{MnO}_{2}$, respectively. ${ }^{65}$ Bands at II50 and $202 \mathrm{~cm}^{-1}$ correspond to $\alpha$-quartz. ${ }^{75}$ Bands at 455,398 , and $143 \mathrm{~cm}^{-1}$ can be interpreted in two ways on the basis of the literature: either the three bands correspond to bindheimite $\left(\mathrm{Pb}_{2} \mathrm{Sb}_{2} \mathrm{O}_{7}\right)^{22}$ either to $\alpha$-quartz, ${ }^{22}$ $\beta-\mathrm{MnO}_{2}{ }^{65}$ and anatase. ${ }^{48}$ Taking into account that the color of the bead is blue and that by elemental analysis the intensity of $\mathrm{Pb}$ and $\mathrm{Sb}$ is very low, the second indication for the band identification is more probable. X-rays found $\mathrm{Ca}, \mathrm{Mn}$, and $\mathrm{Fe}$ to be major elements. $\mathrm{Co}$ and $\mathrm{Ni}$ are also observed, and minor elements such as $\mathrm{Cu}, \mathrm{As}, \mathrm{Sr}$, and $\mathrm{P}$ were also identified. The Kindoki type 12 bead was analyzed with Raman spectroscopy on the white (corroded) area and on the blue dark one. Cassiterite $\left(\mathrm{SnO}_{2}\right)^{76}$ or calcium antimonate $\left(\mathrm{CaSb}_{2} \mathrm{O}_{6}\right)^{20,22}$ was identified by the bands at 634 and $282 \mathrm{~cm}^{-1}$. The two compounds seem to have similar bands in this region and simultaneously to the absence of other bands it is difficult to assign the bands either to the one or the other compound. From the dark blue area, bands at 633, 625, 396, 390, and 38I are attributed to $\gamma-\mathrm{Mn}_{2} \mathrm{O}_{3}$ or $\beta-\mathrm{MnO}_{2}, \alpha-\mathrm{MnO}_{2}, \beta-\mathrm{MnO}_{2}$, and $\alpha-\mathrm{Mn}_{2} \mathrm{O}_{3}$, respectively. ${ }^{65} \alpha$-quartz was identified by the bands at approximately 404,387 , and $262 \mathrm{~cm}^{-1} \cdot 22$ $\mathrm{Ca}, \mathrm{Fe}, \mathrm{Mn}, \mathrm{Cu}, \mathrm{Pb}$, and $\mathrm{Bi}$ were identified by elemental analysis.

White Beads. Three types of not corroded white glass beads were studied (Kindoki type 3, two beads from Kindoki types 8-9, one with blue decoration and one with incisions, and Kindoki type 13; see Figure 5). For Kindoki type 3 , a band at $979 \mathrm{~cm}^{-1}$ is attributed to $\beta$-Wollastonite $\left(\mathrm{CaSiO}_{3}\right)^{33}$ and one at $956 \mathrm{~cm}^{-1}$ corresponds to the $v_{1} \mathrm{PO}_{4}$ vibration mode. ${ }^{33,68}$ The latter band, in combination with $\mathrm{Ca}$ found from the elemental analysis, imply the existence of calcium phosphate $\left(\beta-\mathrm{Ca}_{3}\left(\mathrm{PO}_{4}\right)_{2}\right)$, probably used as opacifier. $\alpha$-quartz was identified by the bands at $358,354,181,150 \mathrm{~cm}^{-1} 75$ and anatase by the

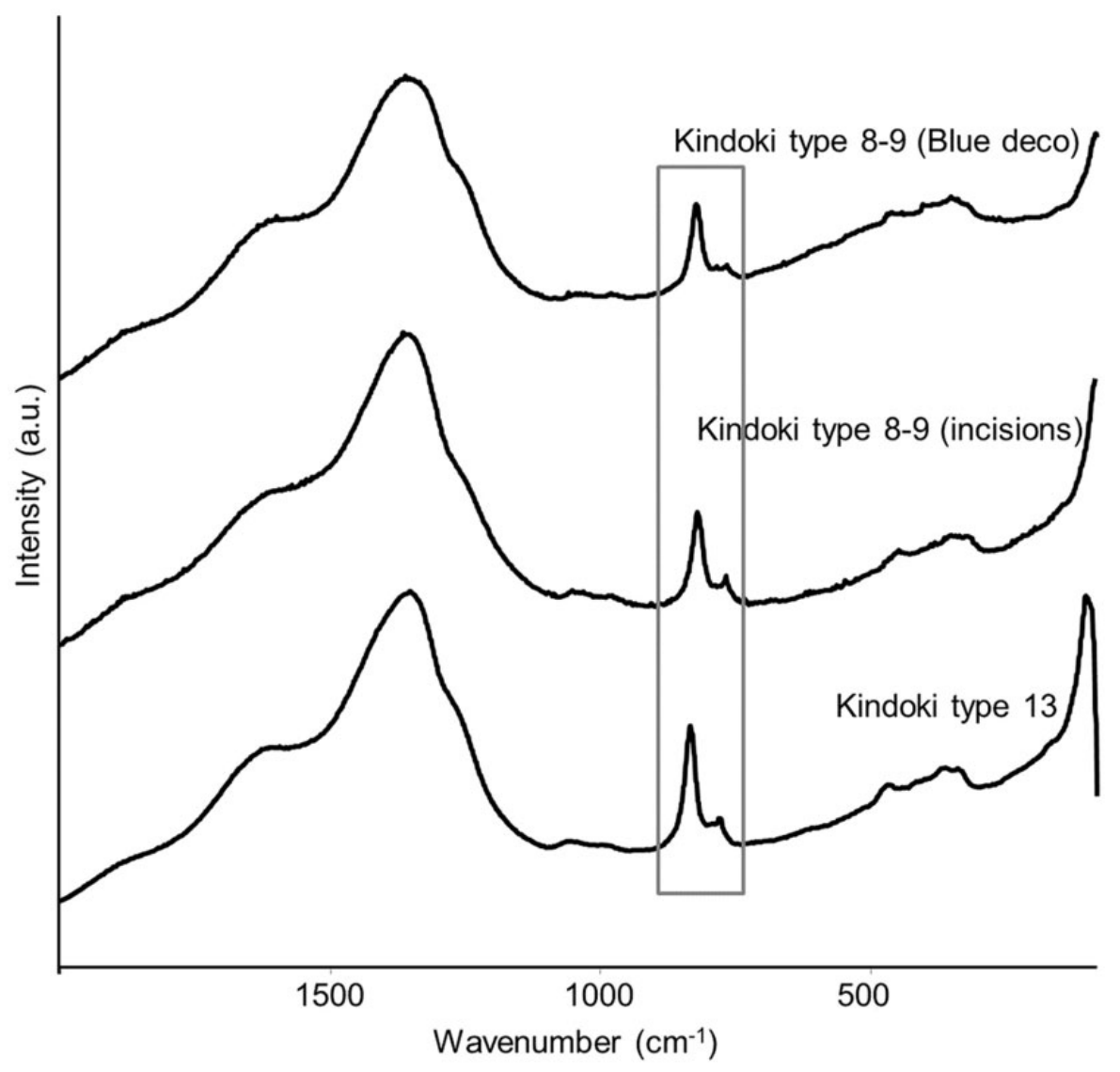

Figure 5. The signature of the lead arsenate $\left(\mathrm{Pb}_{3} \mathrm{AsO}_{\mathrm{n}}\right)$ is clearly visible in all the Raman spectra of beads from this cluster, and might point out a similarity in origin. 
band at $142 \mathrm{~cm}^{-1} .48$ In addition to anatase, also rutile is identified by its strong features at 606 and $448 \mathrm{~cm}^{-1}$. The transition between the two $\mathrm{TiO}_{2}$ phases is related to the firing temperature. ${ }^{59}$ Two bands at 554 and $550 \mathrm{~cm}^{-1}$ (doublet) probably correspond to $\delta \mathrm{Si}-\mathrm{O}-\mathrm{Si} \mathrm{Q}^{3}$ vibrations from the alkali rich silicate. ${ }^{29}$ Elemental analysis revealed the presence of $\mathrm{P}, \mathrm{Ca}, \mathrm{Fe}, \mathrm{As}, \mathrm{Rb}$, and Sr. For Kindoki types 8-9, blue decoration on the bead, bands at 822 and $427 \mathrm{~cm}^{-1}$ correspond to lead arsenate $\left(\mathrm{Pb}_{3} \mathrm{AsO}_{\mathrm{n}}\right)^{60,61}$ Moreover, the band at $620 \mathrm{~cm}^{-1}$ may correspond either to $\alpha-\mathrm{Mn}_{2} \mathrm{O}_{3}{ }^{65}$ or $\beta-\mathrm{MnO}_{2},{ }^{48}$ the band at $615 \mathrm{~cm}^{-1}$ may imply the existence of magnetite ${ }^{67}$ and at $140 \mathrm{~cm}^{-1}$ is attributed to anatase. ${ }^{48} \mathrm{~A}$ band at $813 \mathrm{~cm}^{-1}$, which existed in all the spectra recorded from this bead, is attributed to the symmetric stretching $v_{\mid}$mode of the $\mathrm{AsO}_{4}{ }^{3-}$ free ion, which coincides with the anti-symmetric stretching $v_{3}$ mode. ${ }^{77} A$ rather intense band at $946 \mathrm{~cm}^{-1}$ is likely to correspond to the abundance of precipitated Ca-rich nanosilicates. ${ }^{22}$ On the Kindoki types 8-9, with incisions, again lead arsenate $\left(\mathrm{Pb}_{3} \mathrm{AsO}_{n}\right)$ was identified by the bands at $820,600,454$, and $34 \mathrm{I} \mathrm{cm}^{-1}$. ${ }^{60,61}$ Bands at 400 , $374,344 \mathrm{~cm}^{-1}$ and $143 \mathrm{~cm}^{-1}$ correspond to $\alpha$-quartz ${ }^{22,78}$ and anatase, ${ }^{48}$ respectively. Bands at 1728, 1634, 1605, and $1453 \mathrm{~cm}^{-1}$ are attributed to a Ca-oxalate degradation product (weddelite or whewellite). ${ }^{69}$ For the two beads, elements such as $\mathrm{Ca}, \mathrm{Fe}, \mathrm{Ni}, \mathrm{As}$, and $\mathrm{Pb}$ can be identified as major elements. At Kindoki types 8-9, with blue decoration, Co was also identified and it contributes to the blue decoration probably along with the manganese oxides. At the bead with the incisions from the same type, $\mathrm{Sn}$ was also found. At Kindoki type 13, again lead arsenate $\left(\mathrm{Pb}_{3} \mathrm{AsO}_{n}\right)$ was identified from the bands at 820, 347, and $321 \mathrm{~cm}^{-1} \cdot 60,61$ A band at $452 \mathrm{~cm}^{-1}$ is attributed to $\alpha$-quartz. ${ }^{22}$ The elements found in this bead are $\mathrm{Ca}, \mathrm{Fe}$, $\mathrm{As}, \mathrm{Pb}$, and $\mathrm{Bi}$.

The elemental composition of the Kindoki type 3 bead seems to be different of the other three white glass ones. Molecularly, micro-Raman spectroscopy revealed the usage of different opacifiers for the Kindoki type 3 and the Kindoki types 8-9 and 13 beads.

Red-on-White Beads. The Kindoki type 2 beads are the only red glasses found in the tombs. Micro-Raman spectroscopy (785 $\mathrm{nm}$ excitation) revealed the existence of lead arsenate ions by the characteristic bands at 863 and $836 \mathrm{~cm}^{-1}{ }^{64}$ It is likely that the counter-ion is $\mathrm{Pb}$ and, as in the spectra collected with the other laser $(532 \mathrm{~nm})$, the lead arsenate is identified on the basis of the band at $824 \mathrm{~cm}^{-1}$. 22,79 Again with the red laser, calcite (bands at III4, 1097, and $\left.745 \mathrm{~cm}^{-1}\right),{ }^{80}$ phosphate $\left(v_{1} \mathrm{PO}_{4}\right.$ vibration mode at $966 \mathrm{~cm}^{-1}$ ), 33,68 and $\mathrm{MnO}$ (approximately $600 \mathrm{~cm}^{-1}$ ) 65 were identified. Traces of Ca-oxalates are also present (approximately 1450 and $1715 \mathrm{~cm}^{-1}$ ). ${ }^{69}$

With the green laser, calcite $\left(\mathrm{CaCO}_{3}\right)$ was identified by the band at $1085 \mathrm{~cm}^{-1}, 48$ and $\alpha$-quartz by the bands at 400 and $336 \mathrm{~cm}^{-1}$. 22 The bands at 960 and $451 \mathrm{~cm}^{-1}$ are attributed to anglesite $\mathrm{PbSO}_{4}{ }^{81}$ and that at $141 \mathrm{~cm}^{-1}$ to anatase. $^{48}$

Unfortunately, no compounds that could contribute to the red color were identified. Lead arsenate $\left(\mathrm{Pb}_{3} \mathrm{AsO}_{n}\right)$ is probably used as an opacifier of the white glass and calcite $\left(\mathrm{CaCO}_{3}\right)$ and anglesite $\left(\mathrm{PbSO}_{4}\right)$ come from the altered white, yellow, and purple surface of the beads. From the elemental analysis $\mathrm{Ca}, \mathrm{Fe}, \mathrm{Cu}, \mathrm{As}, \mathrm{Sn}, \mathrm{Sb}$, and $\mathrm{Pb}$ were found. One of the most known ancient recipes for obtaining red glass was the combined use of copper and iron, usually in lead-rich matrix. ${ }^{22,82}$ The red color was obtained by precipitation of copper compounds, in form of metal and/or oxide. ${ }^{82-84}$ Iron was used for darkening the shade of the red glass and simultaneously as a flux for promoting the formation of coloring particles. ${ }^{85}$ The lead containing glass of the Kindoki type 2 was probably colored in that way, though the $\mathrm{Cu}$ amount in the mixture is relatively low compared with iron and lead.

Blown Silvered Beads. These beads consist of clear glass coated on the interior with a metallic layer. Micro-Raman analysis on the glass revealed phosgenite $\left(\mathrm{Pb}_{2} \mathrm{CO}_{3} \mathrm{Cl}_{2}\right)$ by the bands at 1067, 269, 159, and $126 \mathrm{~cm}^{-1}$ and cerussite $\left(\mathrm{PbCO}_{3}\right)$ by the bands at 1054 and $226 \mathrm{~cm}^{-1}$. ${ }^{81} \mathrm{~A}$ band at $314 \mathrm{~cm}^{-1}$ can be attributed to fluorite $\left(\mathrm{CaF}_{2}\right){ }^{22}$ With $\mathrm{hXRF}$ it was not possible to obtain separate measurements from the metallic coating and the glass. The elements present in high intensity are $\mathrm{Fe}, \mathrm{As}, \mathrm{Sn}, \mathrm{Pb}$, and $\mathrm{Bi}$. The coating is a silver-colored layer of $\mathrm{Pb}$, probably in an alloy with $\mathrm{Bi}$ and $\mathrm{Sn} .{ }^{18}$ Other elements identified are $\mathrm{Cu}$, $\mathrm{Zn}$, and $\mathrm{Cr}$.

An overview of the previously discussed results can be found in Table 5 .

\section{Chemometrics on Glass Beads}

Chemometrical methods were applied in order to differentiate between glass bead samples. PCA was used as a data extraction method that reduces the number of variables. These limited number of variables contain maximal variance.

Principal component analysis, performed on hXRF results, was used in order to find natural groupings, taking into account the most significant variables, without a priori knowledge of reference spectra and characteristics. During PCA, a new set of axes is constructed such that each principal component axis is orthogonal to the others and captures maximum variance over the spectra. On these principal components axes, every measurement can be described by its coordinates. ${ }^{86}$ Principal component analysis starts from original correlated variables and by the use of eigenvalue-eigenvector matrix operations on the $\mathrm{N} \times \mathrm{m}$ data matrix ( $\mathrm{N}$ points in an m-dimensional hyperspace) produces new uncorrelated variables. ${ }^{87}$ 


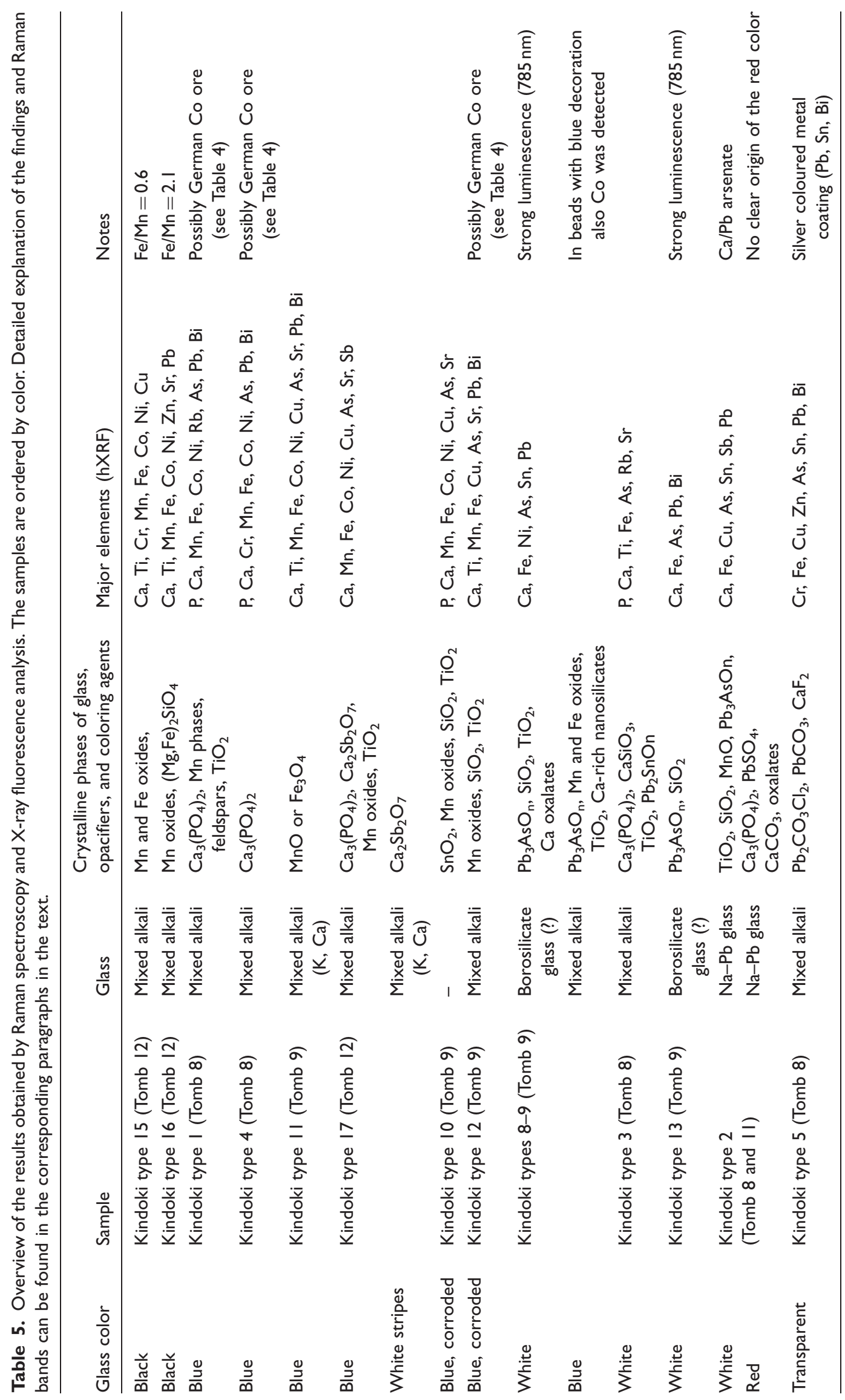


In order to perform PCA analysis, several steps were followed. This approach was applied on the hXRF results of glass beads in order to group them and compare the results with the micro-Raman glass identification grouping. All the beads were measured under similar conditions and the spectra were fitted with AXIL. ${ }^{34}$ Unique fitting models were created for each bead separately. With these models, and the via microxrf2 program, $^{35}$ the large number of spectra per type and tomb were analyzed. All the fitted hXRF spectra were collected, grouped per type and tomb, and normalized by iron. Insignificant elements for the analysis such as $\mathrm{Cl}, \mathrm{Ar}$ (from the air), $\mathrm{Rh}$ ( $\mathrm{K}$ and $\mathrm{L}$ lines, from the source), and $\mathrm{Bi}$ were excluded from the data set. No scaling was applied. Outlier labelling was performed via SPSS 22 (IBM). A g value of 2.2 was used for the calculation of the upper and lower limits (quartiles) of the Gaussian distribution, in order to exclude all the measurements that fall out of the this distribution for each element. ${ }^{88,89}$ In literature, $\mathrm{g}=1.5$ is also sometimes used, but it is proven to identify also measurements which are in the Gaussian distribution. ${ }^{90}$

After outlier labeling, the elements $\mathrm{S}, \mathrm{Rb}$, and $\mathrm{Zr}$ were excluded because they gave zero values for all the beads. In a next step, probability plots ( $\mathrm{P}-\mathrm{P}$ plots) were generated to check the remaining elements for normality. P-P plots indicate normal distribution of the data by plotting the empirical data against a theoretical normal distribution. If the data are normally distributed, this will result in a straight line with positive slope. ${ }^{91}$ The elements $\mathrm{Mg}, \mathrm{Al}, \mathrm{P}$, and $\mathrm{Zn}$ were excluded. $\mathrm{Cu}$ and $\mathrm{Mn}$ were left out of the clustering because there are not core elements for glass and are present in certain types of beads. $\mathrm{Ca}$ and $\mathrm{K}$ were also excluded because they can be contamination from the burial environment and moreover $\mathrm{Ca}$ can also serve as an opacifier in selected types. Finally, PCA was performed, taking into account the following normally distributed elements: $\mathrm{Si}, \mathrm{Ti}, \mathrm{V}, \mathrm{Cr}, \mathrm{Co}, \mathrm{Ni}, \mathrm{As}, \mathrm{Sr}$ ( $\mathrm{K}$ lines), and $\mathrm{Sb}$ and $\mathrm{Pb}$ ( $L$ lines), with a fixed amount of factors equal to the elements used for the analysis. All possible matches of the principal components were tested and it was decided that the best grouping was performed by PC2 and PC4 (Figure SI and Figure S2, Figure 6).

Principal component analysis was able to cluster each type of bead using 10 elements. As can be seen from Figure 6, beads from Kindoki type 2 (red-on-white) measured from two tombs (nos. 8 and II) seem to have a chemical resemblance. Macroscopic observation, which was performed by the archaeologists, attributed these beads from the two tombs to one type, which is confirmed from chemometrics. This bead typology is also known as "Cornalina d'Aleppo". It was likely produced in Venice and exported to Africa and America. ${ }^{3,5,7,18}$ Kindoki type I

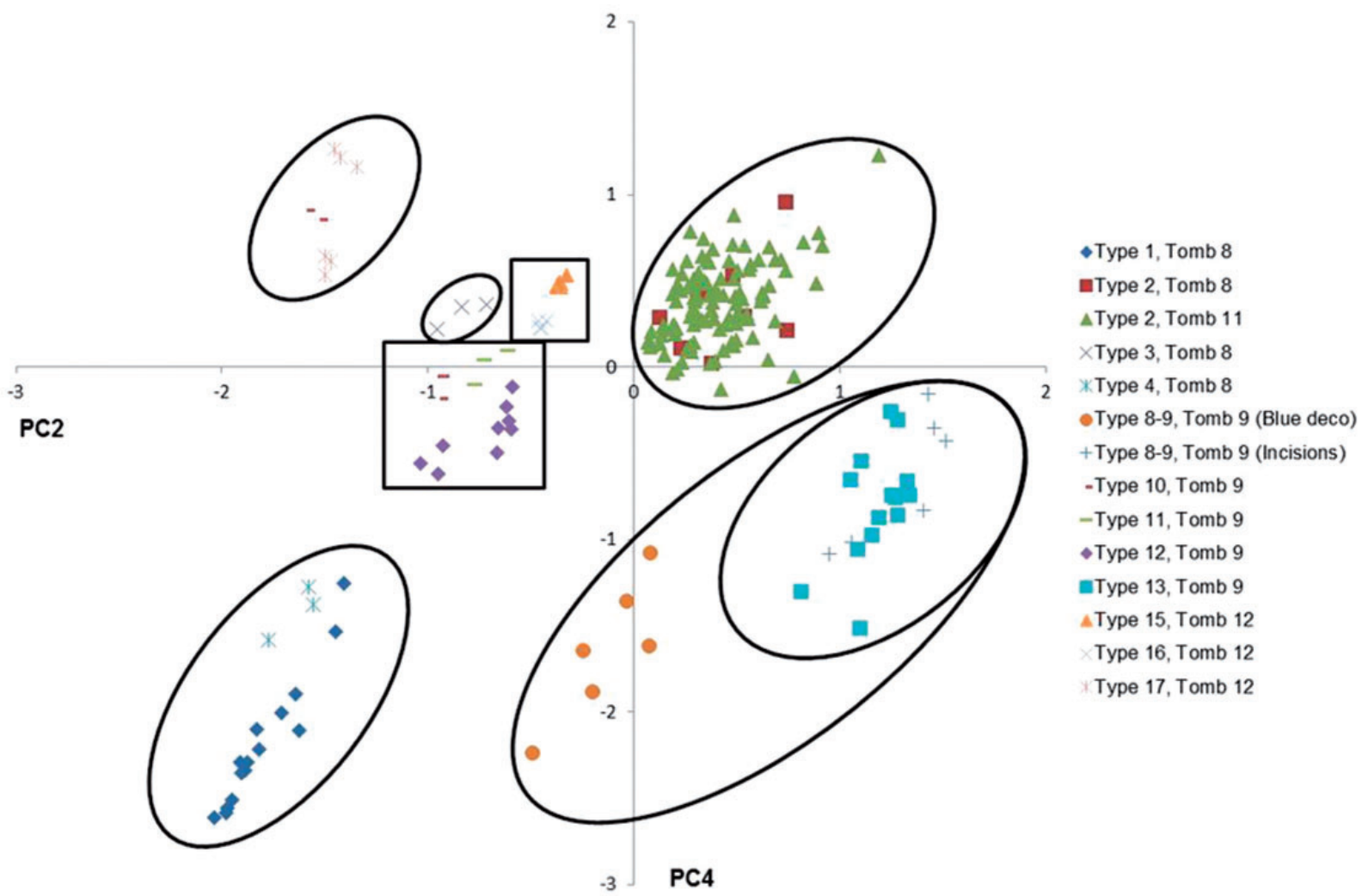

Figure 6. Score plot for PC2 and PC4. Each bead is demonstrated according to type and tomb. 
(dark blue) and Kindoki type 4 (dark blue) beads seem to belong to the same group. It is clear from various independent factors that the glass is of the mixed alkali type, and that a calcium containing phase, such as bone white, has been added as insoluble crystals in the glass of these types. The similarity in the Raman spectra seems to correspond to a similar geographical origin.

Beads from Kindoki type 8-9 (opaque white, incisions) and Kindoki type 13 (opaque white) cluster together with Kindoki type 8-9 (opaque white, blue decorations). These three bead types have the same type of glass but Kindoki type 8-9 (opaque white, blue decorations) has a decorative layer of blue glass that distinguishes it from the other two. Kindoki type 3 (yellowish white) and Kindoki type 17 (navy blue with white stripes) represent two separate groups. Lastly, two clusters of beads are formed: by Kindoki type II (dark blue) and Kindoki type 12 (dark blue), and Kindoki type 15 (black) and Kindoki type 16 (black). Kindoki type 10 (blue) seems to belong to two groups, but the fact that it is highly corroded and not a lot of measurements were performed on it, allows its exclusion from these groups. Kindoki type 10 does not cluster with any group described before.

Grouping of glass performed by micro-Raman analysis demonstrated similar results. In this case, chemometrics of $\mathrm{hXRF}$ results and molecular characterization of the glass were able to group the glass beads successfully. Moreover, the clear results from the opacifiers found on Kindoki types 8-9 (white with blue decoration or incisions) and Kindoki type I 3 (white with incisions) attribute these beads also to a single group, and probably to the same workshop.

\section{Conclusions}

The combination of elemental and molecular information is necessary to understand the different components of the glass-based beads. The potential of Raman spectroscopy for discriminating between different types of glass is well known. Besides, the qualitative information from $h X R F$ is valuable for the identification of chromophores and to cross-check the Raman results. The application of chemometrics is especially useful to characterize groups of beads.

As no data are published on Raman and hXRF analysis of beads from Western Africa or European beads production, it was difficult to make clear conclusions about the origin of these materials. However, it was possible to group them and to observe a good agreement between typological, chemical, and statistical analysis.

\section{Acknowledgments}

We thank Karlis Karklins (Material Culture Research Section of Parks Canada, Ottawa, Canada) for his help in identifying the glass beads according to international types and giving the chronology of their fabrication, and Dr. D Fehse of the Zoological Museum in
Munich (Germany) for the identification of the Pusula depauperata shells.

\section{Funding}

This work has been financially supported by Concerted Research Action "Archaeometrical Study of the Ghent Altarpiece" (GOA) and by Starting Grant No. 284/26 of the European Research Council awarded to Koen Bostoen and by the Special Research Fund of Ghent University.

\section{Conflict of Interest}

The authors report there are no conflicts of interest.

\section{Supplemental Material}

All supplemental material mentioned in the text, including four tables (Table SI a, b, c and d) and two figures (Figure SI and Figure S2), is available at http://asp.sagepub.com/supplemental.

\section{References}

I. BEADS: Journal of the Society of Bead Researchers. http:// www.beadresearch.org/Pages/Journal_Contents.html [accessed Mar 10 20I5].

2. N.J. Van Der Merwe, S.J. Saitowitz, J.F. Thackeray, M. Hall, C. Poggenpoel. Standardized Analyses of Glass Trade Beads from Mgungundlovu and Ondini, Nineteenth Century Zulu Capitals. South African Archaeol. Bul. 1989. 150: 98-104.

3. W.G.N. van der Sleen. Ancient Glass Beads with Special Reference to the Beads of East and Central Africa and the Indian Ocean. J. Royal Anthropol. Inst. Great Brit. Ireland. 1958. 88(2): 203-216.

4. S.J. Saitowitz, C.G. Sampson. Glass Trade Beads from Rock Shelters in the Upper Karoo. South African Archaeol. Soc. 1992. 47(I56): 94-103.

5. C.R. DeCorse, F.G. Richard, I. Thiaw. Toward a Systematic Analysis of Archeological Beads: A View From the Lower Falemme, Senegal. J. African Archaeol. 2003. I(I): 77-109.

6. K. Karklins. Guide to the Description and Classification of Glass Beads. Glass Beads. 1982, pp. 9-1I.

7. K. Karklins. Glass Beads: A Guide to the Description and Classification of Glass Beads. Ottawa, ON: Parks Canada, 1985.

8. K. Karklins. Glass Beads: The Levin Catalogue of Mid-19th Century Beads; A Sample Book of 19th Century Venetian Beads; Guide to the Description and Classification of Glass Beads. Ottawa, ON: National Historic Parks and Sites Branch Parks Canada, 1985.

9. K. Karklins. Guide to the Description and Classification of Glass Beads Found in the Americas. Beads. 2012. 24: 62-90.

10. L. Dussubieux, C.M. Kusimba, V. Gogte, S.B. Kusimba, B. Gratuze, R. Oka. The Trading of Ancient Glass Beads: New Analytical Data from South Asian and East African SodaAlumina Glass Beads. Archaeometry. 2008. 50(5): 797-82I.

II. P. Robertshaw, M. Wood, E. Melchiorre, R.S. Popelka-Filcoff, M.D. Glascock. Southern African Glass Beads: Chemistry, Glass Sources and Patterns of Trade. J. Archaeol. Sci. 2010. 37(8): $1898-1912$.

12. C.R. DeCorse. Beads as Chronological Indicators in West African Archaeology. Beads. 1989. I: 4I-53. 
I3. R.G.V. Hancock, J. McKechnie, S. Aufreiter, K. Karklins, M. Kapches, M. Sempowski. Non-Destructive Analysis of European Cobalt Blue Glass Trade Beads. J. Radioanal. Nuclear Chem. 2000. 244: 567-573.

14. M.L. Sempowski, A.W. Nohe, R.G.V. Hancock, J.-F. Moreau, F. Kwok, S. Aufreiter. Chemical Analysis of 17th-century Red Glass Trade Beads from Northeastern North America and Amsterdam. Archaeometry. 200I. 43(4): 503-5I5.

I5. B. Clist, P. De Maret, G.-M. De Schryver, M. Kaumba, I. Matonda, E. Cranshof. The KongoKing Project: 2012 Fieldwork Report from the Lower Congo Province (DRC). Nyame Akuma. 2013. 79: 60-73.

16. B.O. Clist, N. Nikis, A. Nkanza Lutayi, J. Overmeire, M. Praet, K. Scheerlink. Le projet KongoKing: Les prospections et fouilles menees en 2014 a Misenga, Sumbi et Ngongo Mbata (Province du Bas-Congo, RDC). Nyame Akuma. 2014. 82: 48-56.

17. K.E. Kidd, M.A. Kidd. A Classification System for Glass Beads for the Use of Field Archaeologists. Beads. 2012. 24: 39-6I.

18. C. Verhaeghe, B. Clist, C. Fontaine, K. Karklins, W. De Clercq. Shell and Glass Beads from the Tombs of Kindoki, Mbanza Nsundi, Lower Congo. Beads. 2014. 33: 22-33.

19. N. Welter, U. Schüssler, W. Kiefer. Characterisation of Inorganic Pigments in Ancient Glass Beads by Means of Raman Microspectroscopy, Microprobe Analysis and X-Ray Diffractometry. J. Raman Spectrosc. 2007. 38(I): II3-121.

20. V. Gedzevičiūte, N. Welter, U. Schüssler, C. Weiss. Chemical Composition and Colouring Agents of Roman Mosaic and Millefiori Glass, Studied by Electron Microprobe Analysis and Raman Microspectroscopy. Archaeol. Anthropol. Sci. 2009. I (I): I5-29.

2I. E. Basso, C. Invernizzi, M. Malagodi, M.F. La Russa, D. Bersani, P.P. Lottici. Characterization of Colorants and Opacifiers in Roman Glass Mosaic Tesserae Through Spectroscopic and Spectrometric Techniques. J. Raman Spectrosc. 2014. 45(3): 238-245.

22. P. Ricciardi, P. Colomban, A. Tournié, M. Macchiarola, N. Ayed. A Non-Invasive Study of Roman Age Mosaic Glass Tesserae by Means of Raman Spectroscopy. J. Archaeol. Sci. 2009. 36(I I): 255I-2559.

23. A. Cesaratto, P. Sichel, D. Bersani, P.P. Lottici, A. Montenero, E. Salvioli-Mariani. Characterization of Archeological Glasses by Micro-Raman Spectroscopy. J. Raman Spectrosc. 2010. 4I(I2): I682-1687.

24. A. Lima, T. Medici, A. Pires de Matos, M. Verità. Chemical Analysis of 17th Century Millefiori Glasses Excavated in the Monastery of Sta. Clara-A-Velha. "Portugal: Comparison with Venetian and Façon-De-Venise Production. J. Archaeol. Sci. 2012. 39(5): 1238-1248.

25. A. Bonneau, J.-F. Moreau, R.G.V. Hancock, K. Karklins. Archaeometrical Analysis of Glass Beads-Potentials, Limitations and Results. Beads. 2014. 26: 35-46.

26. P. Colomban, O. Paulsen. Non-Destructive Determination of the Structure and Composition of Glazes by Raman Spectroscopy. J. Am. Ceram. Soc. 2005. 88(2): 390-395.

27. P. Colomban. Case Study: Glasses, Glazes and Ceramics-Recognition of Ancient Technology from the Raman Spectra. In: H.G.M. Edwards, J.M. Chalmers (eds) Raman Spectroscopy in Art and Archaeology. Cambridge, UK: The Royal Society of Chemistry, 2005, pp. 192-205.
28. P. Colomban, A. Tournié, L. Bellot-Gurlet. Raman Identification of Glassy Silicates Used in Ceramics, Glass and Jewellery: A Tentative Differentiation Guide. J. Raman Spectrosc. 2006. 37(8): 84I-852.

29. L. Robinet, C. Coupry, K. Eremin, C. Hall. The Use of Raman Spectrometry to Predict the Stability of Historic Glasses. J. Raman Spectrosc. 2006. 37(7): 789-797.

30. L. Robinet, A. Bouquillon, J. Hartwig. Correlations Between Raman Parameters and Elemental Composition in Lead and Lead Alkali Silicate Glasses. J. Raman Spectrosc. 2008. 39(5): 618-626.

3I. P. Robertshaw, M. Wood, A. Haour, K. Karklins, H. Neff. Chemical Analysis, Chronology, and Context of a European Glass Bead Assemblage from Garumele, Niger. J. Archaeol. Sci. 20I4. 4I: 59I-604.

32. K.E. Kidd, M.A. Kidd. A Classification System for Glass Beads for the Field Archeologist. Proceedings of the 1982 Glass Trade Bead Conference. Rochester Museum and Science Center Research Division. 1983. 219-257.

33. P. Colomban. Raman Spectrometry, a Unique Tool to Analyze and Classify Ancient Ceramics and Glasses. Appl. Phys. A: Mater. Sci. Process. 2004. 79(2): 167-170.

34. B. Vekemans, K. Janssens, L. Vincze, F. Adams, P. Van Espen. Analysis of X-Ray Spectra by Iterative Least Squares (AXIL): New Developments. X-Ray Spectrom. 1994. 23(6): 278-285.

35. B. Vekemans, K. Janssens, L. Vincze, F. Adams, P. Van Espen. Comparison of Several Background Compensation Methods Useful for Evaluation of Energy-Dispersive X-Ray Fluorescence Spectra. Spectrochim. Acta, Part B. 1995. 50(2): 149-169.

36. R.B. Scott, A.J. Shortland, P. Degryse, M. Power, K. Domoney, S. Boyen. In Situ Analysis of Ancient Glass: 17th Century Painted Glass from Christ Church Cathedral, Oxford and Roman Glass Vessels. J. Soc. Glass Technol. 2012. 53(2): 65-73.

37. J.N. Miller, J.C. Miller. Statistics and Chemometrics for Analytical Chemistry. Upper Saddle River, NJ: Pearson/ Prentice Hall, 2005.

38. P. Vandenabeele. Practical Raman spectroscopy: An Introduction. Chichester, UK: John Wiley \& Sons, 2013.

39. R.L. Frost, W. Martens, J.T. Kloprogge, P.A. Williams. Raman Spectroscopy of the Basic Copper Chloride Minerals Atacamite and Paratacamite: Implications for the Study of Copper, Brass and Bronze Objects of Archaeological Significance. J. Raman Spectrosc. 2002. 33(I0): 80I-806.

40. W. Martens, R.L. Frost, J.T. Kloprogge, P.A. Williams. Raman Spectroscopic Study of the Basic Copper SulphatesImplications for Copper Corrosion and Bronze Disease. J. Raman Spectrosc. 2003. 34(2): |45-I5I.

4I. V. Hayez, J. Guillaume, A. Hubin, H. Terryn. Micro-Raman Spectroscopy for the Study of Corrosion Products on Copper Alloys: Setting up of a Reference Database and Studying Works of Art. J. Raman Spectrosc. 2004. 35(89): 732-738.

42. R. Cesareo, M. Ferretti, G.E. Gigante, G. Guida, P. Moioli, S. Ridolfi. The Use of a European Coinage Alloy to Compare the Detection Limits of Mobile XRF Systems. A Feasibility Study. X-Ray Spectrom. 2007. 36(3): I67-I72.

43. L. Dussubieux, P. Robertshaw, M.D. Glascock. LA-ICP-MS Analysis of African Glass Beads: Laboratory Inter- 
Comparison with an Emphasis on the Impact of Corrosion on Data Interpretation. Int. J. Mass Spectrom. 2009. 284(I-3): |52-161.

44. L. Bergamonti, D. Bersani, D. Csermely, P.P. Lottici. The Nature of the Pigments in Corals and Pearls: A Contribution from Raman Spectroscopy. Spectrosc. Lett. 20II. 44(7-8): 453-458.

45. L. Bergamonti, D. Bersani, S. Mantovan, P.P. Lottici. MicroRaman Investigation of Pigments and Carbonate Phases in Corals and Molluscan Shells. Eur. J. Mineral. 20I3. 25(5): 845-853.

46. R. Downs. The RRUFF Project: An Integrated Study of the Chemistry, Crystallography, Raman and Infrared Spectroscopy of Minerals. Presented at: 19th General Meeting of the International Mineralogical Association. Kobe, Japan. 2006. 47.

47. H.G.M. Edwards, S.E.J. Villar, J. Jehlicka, T. Munshi. FT-Raman Spectroscopic Study of Calcium-Rich and Magnesium-Rich Carbonate Minerals. Spectrochim. Acta, Part A. 2005. 6I(I0): 2273-2280.

48. H.G.M. Edwards, E. Newton, J. Russ. Raman Spectroscopic Analysis of Pigments and Substrata in Prehistoric Rock Art. J. Mol. Struct. 2000. 550-55I: 245-256.

49. D. Lin-Vien, N.B. Colthup, W.G. Fateley, J.G. Grasselli. The Handbook of Infrared and Raman Characteristic Frequencies of Organic Molecules. Amsterdam, the Netherlands: Elsevier, 1991.

50. I.A. Karampas, M.G. Orkoula, C.G. Kontoyannis. A Quantitative Bioapatite/Collagen Calibration Method Using Raman Spectroscopy of Bone. J. Biophoton. 2013. 6(8): 573-586.

5I. R. Withnall, B.Z. Chowdhry, J. Silver, H.G.M. Edwards, L.F.C. de Oliveira. Raman Spectra of Carotenoids in Natural Products. Spectrochim. Acta, Part A. 2003. 59(10): 2207-2212.

52. P. McMillan. Structural Studies of Silicate Glasses and MeltsApplications and Limitations of Raman Spectroscopy. Am. Mineral. 1984. 69: 622-644.

53. B.O. Mysen, L.W. Finger, D. Virgo, F.A. Seifert. Curve-Fitting of Raman Spectra of Silicate Glasses. Am. Mineral. 1982. 67(7-8): 686-695.

54. C.J. Brinker, R.J. Kirkpatrick, D.R. Tallant, B.C. Bunker, B. Montez. NMR Confirmation of Strained "Defects" in Amorphous Silica. J. Non-Cryst. Solids. 1988. 99(2-3): 418-428.

55. B.O. Mysen, D. Virgo, C.M. Scarfe. Relations Between the Anionic Structure and Viscosity of Silicate Melts-a Raman Spectroscopic Study. Am. Mineral. 1980. 65(7-8): 690-7I0.

56. S.A. Brawer, W.B. White. Raman Spectroscopic Investigation of the Structure of Silicate Glasses. I. The Binary Alkali Silicates. J. Chem. Phys. 1975. 63(6): 242I-2432.

57. A. Tournié, L.C. Prinsloo, P. Colomban. Raman Spectra Database of the Glass Beads Excavated on Mapungubwe Hill and K2, Two Archaeological Sites in South Africa. arXiv20 I0. arXiv1012.1465. 2010.

58. N. Carmona, I. Ortega-Feliu, B. Gómez-Tubío, M.A. Villegas. Advantages and Disadvantages of PIXE/PIGE, XRF and EDX Spectrometries Applied to Archaeometric Characterisation of Glasses. Mater. Charact. 2010. 6I(2): 257-267.

59. C.A. Chen, Y.S. Huang, W.H. Chung, D.S. Tsai, K.K. Tiong. Raman Spectroscopy Study of the Phase Transformation on
Nanocrystalline Titania Films Prepared via Metal Organic Vapour Deposition. J. Mater. Sci.: Mater Electron. 2009. 20: S303-S306.

60. L.C. Prinsloo, A. Tournié, P. Colomban. A Raman Spectroscopic Study of Glass Trade Beads Excavated at Mapungubwe Hill and K2, Two Archaeological Sites in Southern Africa, Raises Questions About the Last Occupation Date of the Hill. J. Archaeol. Sci. 20I I. 38(I2): 3264-3277.

6I. C. Miguel, A. Claro, A.P. Gonçalves, V.S. Muralha, M.J. Melo. A Study on Red Lead Degradation in a Medieval Manuscript Lorvao Apocalypse (I I89). J. Raman Spectrosc. 2009. 40(I2): 1966-1973.

62. S.J. Kelloway, N. Kononenko, R. Torrence, E.A. Carter. Assessing the Viability of Portable Raman Spectroscopy for Determining the Geological Source of Obsidian. Vib. Spectrosc. 2010. 53(I): 88-96.

63. L. Zhou, H. Lin, W. Chen, L. Luo. IR and Raman Investigation on the Structure of $(100-\mathrm{X}) \mathrm{B} 2 \mathrm{O} 3-\mathrm{X}[0.5 \mathrm{BaO}-0.5 \mathrm{ZnO}]$ Glasses. J. Phys. Chem. Solids. 2008. 69(I0): 2499-2502.

64. K. Müller, V.S.T. Ciminelli, M.S.S. Dantas, S. Willscher. A Comparative Study of as(III) and as(v) in Aqueous Solutions and Adsorbed on Iron Oxy-Hydroxides by Raman Spectroscopy. Water Res. 2010. 44(19): 5660-5672.

65. F. Buciuman, F. Patcas, R. Craciun, D.R.T. Zahn. Vibrational Spectroscopy of Bulk and Supported Manganese Oxides. Phys. Chem. Chem. Phys. 1999. I(I): I85-190.

66. H. Gomes, P. Rosina, P. Holakooei, T. Solomon, C. Vaccaro. Identification of Pigments Used in Rock Art Paintings in Gode Roriso-Ethiopia Using Micro-Raman Spectroscopy. J. Archaeol. Sci. 2013. 40: 4073-4082.

67. D.L.A. de Faria, S. Venâncio Silva, M.T. de Oliveira. Raman Microspectroscopy of Some Iron Oxides and Oxyhydroxides. J. Raman Spectrosc. 1997. 28(II): 873-878.

68. G. Penel, G. Leroy, C. Rey, E. Bres. MicroRaman Spectral Study of the PO 4 and CO 3 Vibrational Modes in Synthetic and Biological Apatites. Calcif. Tissue Int. 1998. 63(6): $475-481$.

69. R.L. Frost, M.L. Weier. Raman Spectroscopy of Natural Oxalates at 298 and 77 K. J. Raman Spectrosc. 2003. 34(10): 776-785.

70. A. Chopelas. Single Crystal Raman Spectra of Forsterite, Fayalite, and Monticellite. Am. Mineral. 1991. 76: II0I-II09.

7I. M. Verità, A. Renier, S. Zecchin. Chemical Analyses of Ancient Glass Findings Excavated in the Venetian Lagoon. J. Cult. Herit. 2002. 3(4): 26I-27I.

72. A. Zucchiatti, L. Canonica, P. Prati, A. Cagnana, S. Roascio, A.C. Font. PIXE Analysis of $\mathrm{v}-\mathrm{XVI}$ Century Glasses from the Archaeological Site of San Martino Di Ovaro (Italy). J. Cult. Herit. 2007. 8(3): 307-3।4.

73. T. Calligaro. PIXE in the Study of Archaeological and Historical Glass. X-Ray Spectrom. 2008. 37(2): 169-177.

74. K. Polikreti, J.M.A. Murphy, V. Kantarelou, A.G. Karydas. XRF Analysis of Glass Beads from the Mycenaean Palace of Nestor at Pylos, Peloponnesus, Greece: New Insight into the LBA Glass Trade. J. Archaeol. Sci. 20I I. 38(I I): 2889-2896.

75. A. Hernanz, J.M. Gavira-Vallejo, J.F. Ruiz-López, S. Martin, Á. Maroto-Valiente, R. de Balbín-Behrmann. Spectroscopy of Palaeolithic Rock Paintings from the Tito Bustillo and El 
Buxu Caves, Asturias, Spain. J. Raman Spectrosc. 20 I 2. 43(I I): 1644-1650.

76. L.C. Prinsloo, P. Colomban. A Raman Spectroscopic Study of the Mapungubwe Oblates: Glass Trade Beads Excavated at an Iron Age Archaeological Site in South Africa. J. Raman Spectrosc. 2008. 39(I): 79-90.

77. R. Frost, J. Bouzaid, S. Palmer. The Structure of Mimetite, Arsenian Pyromorphite and Hedyphane-a Raman Spectroscopic Study. Polyhedron. 2007. 26(I3): 2964-2970.

78. H.X. Zhao, Q.H. Li, S. Liu, F.X. Gan. Characterization of Microcrystals in Some Ancient Glass Beads from China by Means of Confocal Raman Microspectroscopy. J. Raman Spectrosc. 2013. 44(4): 643-649.

79. A. Tournié, L.C. Prinsloo, P. Colomban. Raman Classification of Glass Beads Excavated on Mapungubwe Hill and K2, Two Archaeological Sites in South Africa. J. Raman Spectrosc. 2012. 43(4): 532-542.

80. Lin-Gun Liu, T.P. Mernagh. Phase Transitions and Raman Spectra of Calcite at High Pressures and Room Temperature. Am. Mineral. 1990. 75(7-8): 80I-806.

8I. M. Bouchard, D.C. Smith. Catalogue of 45 Reference Raman Spectra of Minerals Concerning Research in Art History or Archaeology, Especially on Corroded Metals and Coloured Glass. Spectrochim. Acta Part A. 2003. 59(I0): 2247-2266.

82. C. Moretti, B. Gratuze. Vetri rossi al rame e avventurina. Confronto di analisi e ricette. Rivista della stazione sperimentale del vetro. 1999. 29(3): |47-160.

83. A.S. Barbone. The Sectilia Panels of Faragola (Ascoli Satriano, Southern Italy): A Multianalytical Study of the Red, Orange and Yellow Glass. Archaeometry. 2008. 50(3): 45I-473.
84. D. Barber, I. Freestone, K. Moulding. "Ancient Copper Red Glasses: Investigation and Analysis by Microbeam Techniques. In: A. Shortland, I. Freestone, T. Rehren (eds) From Mine to Microscope - Advances in the Study of Ancient Technology. Oxford, UK: Oxbow, 2009, pp. II5-127.

85. M. Verità. Tecniche di fabbricazione dei materiali musivi vitrei: indagini chimiche e mineralogiche. In: E. Borsook, F.G. Superbi, G. Pagliarulo (eds) Medieval Mosaic: Light. Color. Materials. Milan, Italy: Silvana Editoriale, 2000, pp. 47-64.

86. P. Vandenabeele, L. Moens. Micro-Raman Spectroscopy of Natural and Synthetic Indigo Samples. Analyst. 2003. 128(2): 187-193.

87. C. Papachristodoulou, A. Oikonomou, K. loannides, K. Gravani. A Study of Ancient Pottery by Means of X-Ray Fluorescence Spectroscopy, Multivariate Statistics and Mineralogical Analysis. Anal. Chim. Acta. 2006. 573-574: 347-353.

88. J. Tukey. Exploratory Data Analysis. Boston, MA: AddisonWesley Publishing Company, 1977.

89. D. Hoaglin, B. Iglewicz. Fine-Tuning Some Resistant Rules for Outlier Labeling. J. Am. Stat. Assoc. 1987. 82(400): I |47-I I 49.

90. D. Hoaglin. Performance of Some Resistant Rules for Outlier Labeling. J. Am. Stat. Assoc. 1986. 8I(396): 99I-999.

9I. D.S. Moore, G.P. McCabe, B.A. Craig. Density Curves and Normal Distributions. Introduction to the Practice of Statistics. New York, NY: W.H. Freeman and Company, 20I4Chap. I, pp. 68-7I. 8th ed. 